\title{
A numerical study of the pyrolysis effect on autoignited laminar lifted dimethyl ether jet flames in heated coflow air
}

\author{
Ki Sung Jung, Ba Reum Jung ${ }^{\mathrm{a}}$, Sang Hun Kang ${ }^{\mathrm{b}}$, Suk Ho Chung ${ }^{\mathrm{c}}$, Chun Sang Yoo,* \\ ${ }^{a}$ Department of Mechanical Engineering, Ulsan National Institute of Science and Technology (UNIST), \\ Ulsan 44919, Republic of Korea \\ ${ }^{b}$ Department of Aerospace System Engineering, Sejong University, Seoul 05006, Republic of Korea \\ ${ }^{c}$ Clean Combustion Research Center, King Abdullah University of Science and Technology (KAUST), \\ Thuwal, Saudi Arabia
}

\begin{abstract}
The liftoff, autoignition, and stabilization characteristics of autoignited laminar lifted dimethyl ether (DME) jet flames in heated coflow air are numerically investigated by varying the fuel jet velocity, $U_{0}$. The detailed numerical simulations are performed using the laminarSMOKE code with a 55-species detailed kinetic mechanism of DME oxidation. An unusual U-shaped liftoff height, $H_{\mathrm{L}}$, behavior under MILD combustion condition is observed from the simulations, which is qualitatively consistent with previous experimental results. From additional numerical simulations with modified mass diffusivity of hydrogen, it is verified that the decreasing $H_{\mathrm{L}}$ trend of the lifted flames under relatively-low $U_{0}$ conditions is mainly attributed to the fast diffusion of hydrogen generated from the DME pyrolysis. The species transport and displacement speed analyses verify that the differential diffusion effect renders the lifted flames to be leaner at the center of the jet, ultimately leading to the change of their stabilization mechanism from the autoignition to the autoignition-assisted flame propagation mode with increasing $U_{0}$. The chemical explosive mode analysis (CEMA) identifies important variables and reactions contributing to the autoignition of the DME jet flames, through which the fast diffusion rates of small species are found to cause the deviation of 2-D autoignition characteristics from that of 0-D homogeneous ignition. The effects of DME pyrolysis on the characteristics of the autoignited laminar DME jet flames are further investigated by varying the fuel tube length, $L_{\text {res }}$. $H_{\mathrm{L}}$ shows a non-monotonic behavior with increasing $L_{\text {res }}$ because the flame structure changes from a MILD combustion to a tribrachial edge flame and to an
\end{abstract}


attached flame while the stabilization mechanism also changes from the autoignition to the autoignition-assisted flame propagation mode as the degree of the DME pyrolysis increases. Keywords: Dimethyl ether (DME), autoignited laminar lifted jet flame, flame stabilization, MILD combustion, CEMA

\section{Introduction}

Nonpremixed jet flames have received great attention during the past decades because they have been utilized in many practical combustors such as diesel engines, gas turbines, and boilers. When the fuel jet velocity is high enough at a relatively low temperature condition, nonpremixed jet flames are detached from the burner rim and stabilized in the form of lifted flames. However, real combustion devices generally operate under high pressures and temperatures at which autoignition inevitably affects the stabilization of lifted flames. Many studies have been performed to elucidate their stabilization and flame structure characteristics under autoignitive conditions for turbulent flames with various fuels [1-5].

Laminar lifted flames under autoignitive conditions have also been recently investigated because they can play a fundamental role in elucidating the liftoff and stabilization characteristics of corresponding turbulent lifted flames [6-15]. Under non-autoignitive conditions, a laminar lifted flame usually exhibits a tribrachial structure which consists of two rich/lean premixed flame branches and a trailing diffusion flame branch [16]. The intersection point of these three branches is called a tribrachial (or triple) point at which the lifted flame comes to be stabilized by the dynamic balance between the incoming flow speed and flame propagation speed [17]. However, the autoignited laminar lifted flames can be stabilized not only by flame propagation but also by autoignition. Chung and coworkers [6-9] investigated the characteristics of autoignited laminar lifted flames for various fuels, and they found that autoignited lifted jet flames can be stabilized without an external ignition source when the coflow temperature is above a critical value. In addition, they suggested that the

\footnotetext{
*Corresponding authors.

Email address: csyoo@unist.ac.kr (Chun Sang Yoo)
} 
liftoff height, $H_{\mathrm{L}}$, of autoignited laminar lifted jet flames with tribrachial structure can be correlated to the fuel jet velocity, $U_{0}$, and the 0 -D homogenous ignition delay time of the stoichiometric fuel/air mixture based on the fuel tube exit condition, $\tau_{\text {ig,st }}$ : i.e., $H_{\mathrm{L}} \sim U_{0} \tau_{\text {ig,st }}^{2}$. This relation is originally derived from thermal balance between heat release from autoignition and heat loss by diffusion in a jet mixing layer [6], which can be interpreted based on the balance between the autoignition time scale, $\tau_{\mathrm{ig}, \mathrm{st}}$, and the diffusion time scale of $\sqrt{H_{\mathrm{L}} / U_{0}}$. Such correlation can predict the experimental $H_{\mathrm{L}}$ variations satisfactorily for single-component fuels, implying that 0 -D homogeneous ignition delay plays a critical role in determining the liftoff height and stabilization of autoignited laminar lifted jet flames.

Among many fuels utilized for compression ignition engines, dimethyl ether (DME) has been highlighted as a clean high-efficiency fuel due to its low particulate/ $\mathrm{NO}_{\mathrm{x}}$ emissions and high cetane number $[18,19]$. DME can also be used as a fuel additive for enhancing engine performance as an ignition improver because of its low autoignition temperature compared to those of other hydrocarbon fuels [20]. To understand the fundamental characteristics of DME combustion, many experimental and numerical studies have been carried out $[10,12$, 14, 15]. For instance, Krisman et al. [12] performed high-fidelity numerical simulations of laminar lifted DME jet flames in heated air. They found that autoignition can affect the flame structure varying from a tribrachial to a pentabrachial edge flame with increasing temperature. They also found that the lifted DME jet flames can be stabilized by either flame propagation, autoignition, or autoignition-assisted flame propagation mode. Deng et al. $[14,15]$ numerically investigated the characteristics of laminar DME jet flames under highly-autoignitive conditions. Based on the numerical results, they delineated stabilization mechanisms of the autoignited DME jet flames as functions of the fuel jet temperature and velocity.

Recently, Al-Noman et al. [10] experimentally investigated the liftoff characteristics of laminar jet flames of DME in heated coflow air. They found that autoignited lifted flames exhibit either tribrachial edge structure, or moderate or intense low-oxygen dilution (MILD) combustion with faint blue color depending on the degree of nitrogen dilution in the fuel stream. Unlike previous experimental results on liftoff height increasing monotonically with 
the increase in $U_{0}$ for single component fuels [6-8], they observed an unusual ' $U$ '-shaped liftoff height behavior within the MILD combustion regime: $H_{\mathrm{L}}$ decreases with increasing $U_{0}$ for relatively-low $U_{0}$ conditions while $H_{\mathrm{L}}$ increases with increasing $U_{0}$ for relatively-high $U_{0}$ conditions. In fact, the decreasing $H_{\mathrm{L}}$ behavior with increasing $U_{0}$ has been observed for autoignited laminar lifted jet flames of binary mixture fuels such as methane/hydrogen $[8,11]$ and carbon monoxide/hydrogen fuels [21]. The differential diffusion effect of two fuel components is found to lead the decreasing $H_{\mathrm{L}}$ behavior [11]. Since DME can be easily pyrolyzed into small species such as methane, hydrogen, and formaldehyde at high temperature condition $[22,23]$, we may partially explain the U-shaped $H_{\mathrm{L}}$ behavior of the autoignited lifted DME jet flames by the differential diffusion effect of fuel components decomposed from DME. However, the detailed mechanism behind the U-shaped $H_{\mathrm{L}}$ behavior for the single component DME fuel has not been fully explored.

The objective of the present study is, therefore, to elucidate the liftoff characteristics of autoignited laminar lifted DME jet flames, especially the pyrolysis effect of DME on the unusual U-shaped $H_{\mathrm{L}}$ behavior. For this purpose, we perform two-dimensional numerical simulations with a detailed chemical kinetic mechanism of DME oxidation which includes its unimolecular thermal decomposition reactions. Note that the characteristic DME pyrolysis time is much shorter than those for typical hydrocarbon fuels [10]. Thus, DME in the fuel jet can be pyrolyzed into small species along the fuel tube before issuing from the fuel tube exit, and hence, the fuel composition at the fuel tube exit is not pure DME but includes many small species of which mole fractions vary depending on $U_{0}$ and the fuel tube length, $L_{\text {res }}$. Also note that in the present study, the DME fuel jet is highly diluted with nitrogen under autoignitive temperature condition such that its overall flame characteristics are quite different from those of typical non-autoignited lifted flames of which flamebase lies at the stoichiometric mixture fraction isoline. To better understand the liftoff height variation, the stabilization mechanisms of the autoignited laminar lifted DME jet flames are delineated by adopting the species transport budget and displacement speed analyses. The chemical explosive mode analysis (CEMA) is also conducted to figure out the effects of pyrolysis on the autoignition characteristics of the lifted flames. Finally, the effects of DME pyrolysis on 
the liftoff and flame structure characteristics are further investigated by varying the degree of DME pyrolysis with extended fuel tube length.

\section{Numerical methods}

Detailed numerical simulations of laminar lifted DME jet flames in heated coflow air are performed on 2-D axisymmetric coordinates of the radial, $r$-, and the axial, $z-$, directions. The steady conservation equations of mass, momentum, species, and energy are solved using the laminarSMOKE code [24, 25], which is an open-source code based on OpenFOAM [26] for simulations of multi-dimensional compressible laminar reacting flows with skeletal/detailed chemical mechanisms. Details can be found in [24, 25]. To consider the Soret effect, thermal diffusion is included in the species transport equations. Figure 1 shows a schematic of the computational domain. The main domain size is $R_{0} \times L_{z}=6.65 \mathrm{~cm} \times 50 \mathrm{~cm}$ in the $r$-and $z$-directions, respectively. The inner radius of the fuel tube is $0.188 \mathrm{~cm}$ and its thickness is $0.05 \mathrm{~cm}$. A $75 \mathrm{~cm}$ long fuel tube is attached to the domain, which protrudes $1 \mathrm{~cm}$ above the coflow air inlet. Note that the configuration of the present computational domain is identical to those of previous experimental studies $[6-8,10]$.

The DME jet diluted by nitrogen enters from the bottom of the fuel tube with the initial fuel mole fraction, $X_{\mathrm{F}, 0}$, of 0.08 , the initial fuel temperature, $T_{\mathrm{F}}$, of $300 \mathrm{~K}$, and the uniform fuel inlet velocity, $U_{\mathrm{F}}$. Since the temperature boundary condition for the fuel tube wall is set to $T_{0}=980 \mathrm{~K}$, the fuel jet is heated to $T_{0}$ while passing through it and the mean velocity at the fuel tube exit, $U_{0}$, attains the speed of $1.4 \sim 6 \mathrm{~m} / \mathrm{s}$. Normalized velocity profiles at the fuel tube exit for different $U_{0}$ are shown in the supplementary material, which demonstrates that the effect of DME pyrolysis on $U_{0}$ is minimal. The coflow air inlet velocity, $U_{\mathrm{C}}$, is fixed to $1.1 \mathrm{~m} / \mathrm{s}$ in accordance with the previous experiment [10], and the coflow air temperature is set to $T_{0}$. Pressure outlet boundary condition is atmospheric, and zero-gradient boundary condition is applied for all the remaining boundaries. In the $r$-direction, $50 \mu \mathrm{m}$ mesh size is uniformly distributed within $1.5 \mathrm{~cm}$, and a stretched mesh is applied to the remaining area. A uniform $50 \mu \mathrm{m}$ mesh size is used for the $z$ - direction. 


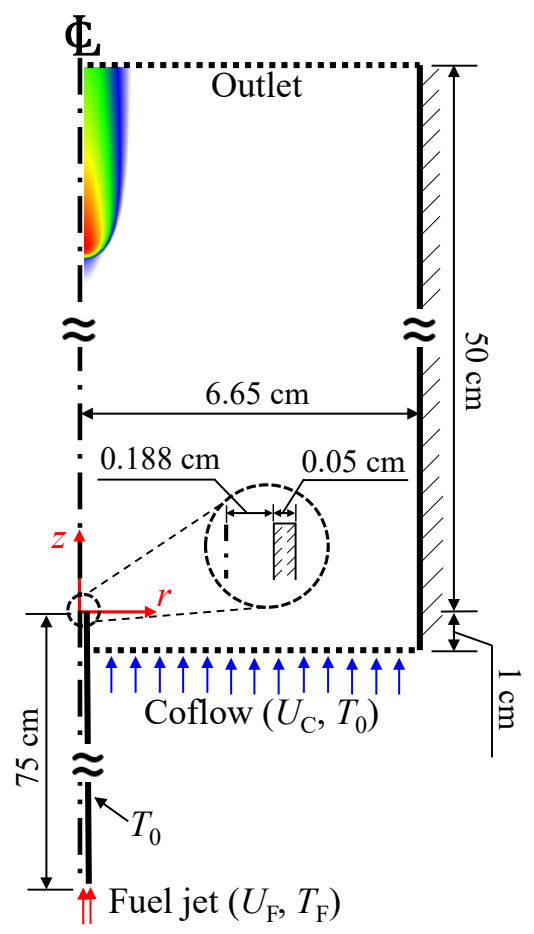

Figure 1: Schematic of the computational domain for simulations of autoignited laminar lifted DME jet flames in heated coflow air. 

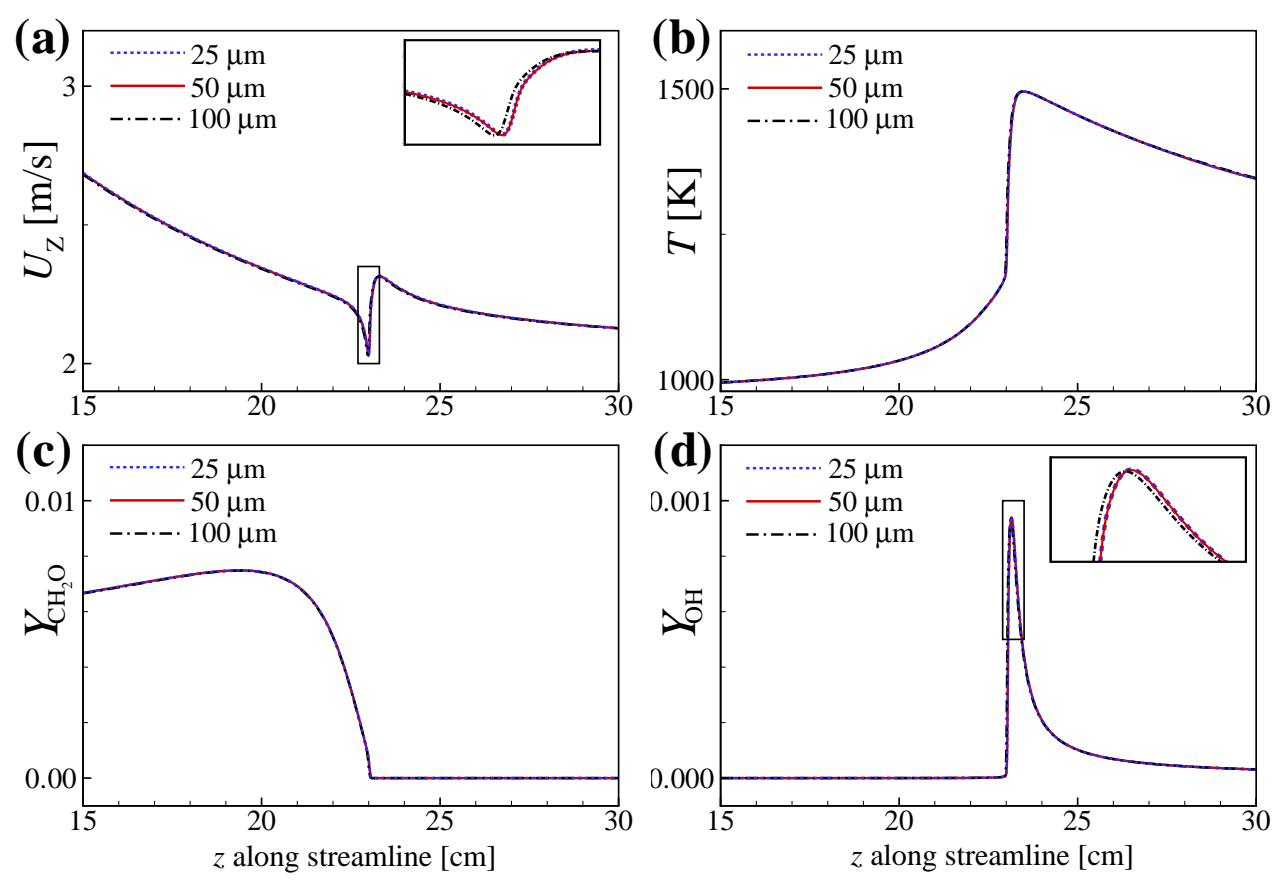

Figure 2: Profiles of (a) axial velocity, (b) temperature, mass fractions of (c) $\mathrm{CH}_{2} \mathrm{O}$ and (d) OH for an autoignited laminar lifted DME jet flame along the streamline passing through the flamebase for three different grid resolutions for $X_{\mathrm{F}, 0}=0.08, T_{0}=980 \mathrm{~K}$, and $U_{0}=5 \mathrm{~m} / \mathrm{s}$.

Figure 2 shows the profiles of axial velocity, temperature, mass fractions of $\mathrm{CH}_{2} \mathrm{O}$ and $\mathrm{OH}$ for an autoignited laminar DME jet flame along the streamline passing through the flamebase for three different grid resolutions, which confirms that the grid resolution of $50 \mu \mathrm{m}$ can reasonably resolve the profiles when compared to the fine grid resolution of $25 \mu \mathrm{m}$. Note that the thinnest flame thickness in the present study, defined by $\delta_{\mathrm{f}} \equiv\left(T_{\max }-T_{\min }\right) / \max (d T / d z)$, along the streamline passing through the flamebase is approximately $1.6 \mathrm{~mm}$. Therefore, the present grid space of $50 \mu \mathrm{m}$ can resolve the flame thickness with approximately 30 grids, which is fine enough to capture the flame structure and liftoff characteristics of the autoignited laminar lifted DME jet flames. We performed another grid convergence test for a tribrachial edge flame in Sec. 5, which verified that $50 \mu \mathrm{m}$ grid space is also fine enough to resolve the structure of the tribrachial edge flame.

A detailed chemical kinetic mechanism of the DME oxidation with 55 species and 290 reactions is adopted for the present study [18]. Figure 3 shows the progress of 0-D DME 


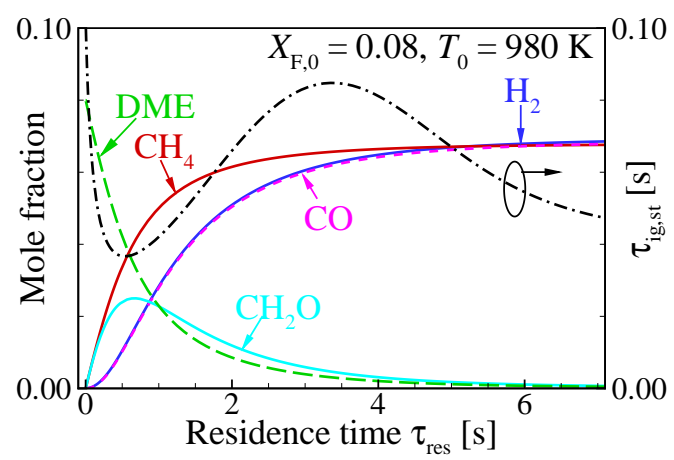

Figure 3: Variations of mole fractions of $\mathrm{DME}, \mathrm{CH}_{4}, \mathrm{H}_{2}, \mathrm{CH}_{2} \mathrm{O}$, and $\mathrm{CO}$ as a function of the residence time, $\tau_{\text {res }}$, from the $0-\mathrm{D}$ pyrolysis of DME/nitrogen mixture with $T_{0}=980 \mathrm{~K}$ and $X_{\mathrm{F}, 0}=0.08$. Dash-dot line represents the corresponding 0-D homogeneous ignition delay of the stoichiometric mixture, $\tau_{\text {ig,st }}$, at given $\tau_{\text {res }}$.

pyrolysis in terms of the variations of important species mole fractions as a function of the residence time, $\tau_{\text {res }}$. The initial conditions of the DME/nitrogen mixture are $T_{0}=980 \mathrm{~K}$ and $X_{\mathrm{F}, 0}=0.08$, which are the same as those of the fuel jet at the fuel tube exit. The variation of the homogenous ignition delay of the stoichiometric mixture, $\tau_{\mathrm{ig}, \mathrm{st}}$, is also shown in the figure, where $\tau_{\mathrm{ig}, \mathrm{st}}$ is evaluated using the temporal mixture composition at given residence time and the initial temperature of $980 \mathrm{~K}$. For 2-D cases, the fuel jet is readily heated to $980 \mathrm{~K}$ within $5 \sim 20 \mathrm{~cm}$ from the tube inlet for $U_{0}=1.4 \sim 6 \mathrm{~m} / \mathrm{s}$. Therefore, $\tau_{\text {res }}$ represents approximately the residence time of the fuel jet within the fuel tube, $L_{\mathrm{res}} / U_{0}$, while $\tau_{\mathrm{ig}, \text { st }}$ denotes the influence of DME pyrolysis on the autoignition of the mixture. As shown in the figure, DME is readily decomposed into other small species as $\tau_{\text {res }}$ increases. It is also found that especially for small $\tau_{\text {res }}, \tau_{\mathrm{ig}, \mathrm{st}}$ varies significantly and non-monotonically with increasing $\tau_{\text {res }}$, which is primarily attributed to the amount of $\mathrm{CH}_{2} \mathrm{O}$ generated from the DME pyrolysis. $\mathrm{CH}_{2} \mathrm{O}$ has been found as an ignition improver at high temperatures $[27,28]$, and as such, we can expect that $\tau_{\text {ig,st }}$ is decreased with increasing $\mathrm{CH}_{2} \mathrm{O}$. Note that $\mathrm{CH}_{2} \mathrm{O}$ varies non-monotonically with $\tau_{\text {res }}$ due to the formation of $\mathrm{CO}$ and $\mathrm{H}_{2}$ [10]. This result implies that DME pyrolysis can significantly alter the ignition characteristics of the DME fuel jet flames, potentially leading to $H_{\mathrm{L}}$ variation. Note that the residence time for 
the fuel jet passing through the fuel tube is $0.125 \sim 0.536 \mathrm{~s}$ for $U_{0}=1.4 \sim 6 \mathrm{~m} / \mathrm{s}$.

Identical to our previous numerical study of autoignited lifted methane/hydrogen jet flames [11], we first obtain a stationary autoignited laminar lifted DME jet flame of $X_{\mathrm{F}, 0}$ $=0.08, T_{0}=980 \mathrm{~K}$, and $U_{0}=5 \mathrm{~m} / \mathrm{s}$ without applying any external ignition source (i.e., literally autoignition). Then, we obtain steady solutions for other lifted flames at different $U_{0}$ by systematically adjusting $U_{0}$ from the first steady solution. To validate our procedure to obtain steady solutions for different autoignited lifted flames, we carried out several transient numerical simulations without applying external sources (now shown here). The results show that the liftoff and flame characteristics of stationary lifted flames obtained by transient simulations are identical to those of the corresponding steady solutions, which demonstrates that the lifted flames in the present simulations are indeed autoignited lifted flames.

\section{Overall characteristics of autoignited flames}

In this section, the unusual U-shaped $H_{\mathrm{L}}$ behavior [10] of autoignited laminar lifted DME jet flames in the MILD combustion regime is numerically investigated. Prior to examining the details of numerical results, we need to clarify several definitions, which will be used through the following sections. First, we determine that autoignition occurs within the computational domain if the homogeneous ignition delay of the stoichiometric mixture evaluated from the fuel mixture at the fuel jet exit is less than one-jet flow-through time of the coflow air, $L_{z} / U_{\text {co }}$, as in our previous study [11]. Thus, the autoignition temperature, $T_{\text {ig }}$, can be defined as the minimum temperature of which $\tau_{\text {ig,st }}$ is less than $L_{z} / U_{\text {co. Since }}$. the components of the fuel mixture at the fuel tube exit can vary with $U_{0}$ by the change in the residence time along the fuel tube as shown in Fig. 3 due to the pyrolysis of DME, $T_{\text {ig }}$ also changes for different $U_{0}$.

Second, combustion process can be defined as MILD combustion when two conditions are satisfied $[29,30] ;$ (1) the inlet temperature of a reactant mixture is greater than its autoignition temperature, $T_{0}>T_{\mathrm{ig}}$, and (2) the maximum allowable temperature increase with respect to the inlet temperature, $T_{\max }-T_{0}$, is smaller than its autoignition temperature, 
or $\left(T_{\max }-T_{0}\right)<T_{\mathrm{ig}}$. In the present study, $T_{0}$ of $980 \mathrm{~K}$ is well above $T_{\mathrm{ig}}$, and hence, $\left(T_{\max }-T_{0}\right) / T_{\text {ig }} \gtrless 1$ can be used as a criterion to determine whether an autoignited lifted DME jet flame exhibits the characteristics of the conventional tribrachial edge flame or the MILD combustion $[6,11,29]$ : a lifted flame with tribrachial edge occurs when $\left(T_{\max }-T_{0}\right) / T_{\mathrm{ig}}$ $>1$ while a lifted flame with MILD combustion appears when $\left(T_{\max }-T_{0}\right) / T_{\text {ig }}<1$ is satisfied. Note that for the present simulations, we adopt $T_{0}$ of $980 \mathrm{~K}$ which is $100 \mathrm{~K}$ larger than that of the experiments [10]. This is because we can only capture the lifted flames within the computational domain by raising $T_{0}$ and make the numerical $H_{\mathrm{L}}$ comparable to that of experiments. This issue has been discussed from previous numerical studies of autoignited laminar lifted flames $[9,11,21]$ and is presumably attributed to the inherent inaccuracy of chemical kinetic mechanisms at the atmospheric pressure and transport data. Note that chemical kinetic mechanisms are usually validated against laminar burning velocities at atmospheric and somewhat elevated pressures of $O(1)$ atm, and against ignition delays in shock tube experiments at high pressures of $O(10)$ atm. Therefore, we believe that the discrepancy is partly because of the limitation of ignition delay time that can be measured in shock tube experiments $(\sim O(10) \mathrm{ms})$. In addition, it can be aggravated by the inaccuracy of DME pyrolysis mechanisms reported in previous experimental studies [31, 32]. To figure out if this issue is related to a specific chemical kinetic mechanism, we compared several different mechanisms $[18,23,33]$ by calculating the 0 -D pyrolysis, ignition delay times, and extinction residence times of highly diluted DME mixtures (see the supplementary material). The results show that their overall pyrolysis process and ignition/extinction behaviors are qualitatively similar to each other, indicating that the discrepancy in the inlet temperature between the experiment and numerical simulations would still exist with different chemical kinetic mechanisms.

Third, for the lifted flames with MILD combustion, temperature and species mass fractions gradually change across the flame zone such that it may be ambiguous to precisely determine the flamebase location with conventional flame markers such as a certain value of temperature or $\mathrm{OH}$ mass fraction $[3,4]$. For the present study, the flamebase is defined as the most upstream point of $\operatorname{Re}\left(\lambda_{\exp }\right)=0$ isoline, where $\lambda_{\exp }$ is an eigenvalue of the Jacobian 
of the chemical source term in the discretized governing equations for the CEMA [11, 34-37]. When a mixture exhibits positive $\operatorname{Re}\left(\lambda_{\exp }\right)$, it is more likely to autoignite if there are no heat and radical losses. However, when a mixture shows negative $\operatorname{Re}\left(\lambda_{\exp }\right)$, it is already burned or fails to autoignite. Therefore, $\operatorname{Re}\left(\lambda_{\exp }\right)=0$ isoline represents the transition from the unburned to the burned mixture, and hence, it can be used as a marker for the flamebase [38].

\subsection{U-shaped $H_{\mathrm{L}}$ behavior}

Figure 4 shows the isocontours of temperature, $T$, and mass fractions of $\mathrm{OH}, \mathrm{H}_{2} \mathrm{O}_{2}$, $\mathrm{CH}_{2} \mathrm{O}$, CO, and $\mathrm{H}_{2}$ of autoignited laminar lifted DME jet flames with MILD combustion for various fuel jet velocities with $T_{0}=980 \mathrm{~K}$ and $X_{\mathrm{F}, 0}=0.08$. Note that the mixture fraction, $\xi$, is evaluated using the Bilger's formula [39]. As in the previous experiments [10], the U-shaped $H_{\mathrm{L}}$ behavior of autoignited laminar lifted DME jet flames is successfully captured from the present simulations. Moreover, the autoignition process featured by the increase of temperature and the build-up of intermediate species such as $\mathrm{H}_{2} \mathrm{O}_{2}$ upstream of the flamebase is readily observed, which implies that autoignition may play an important role in stabilizing the lifted jet flames. It is of interest to note that the mass fractions of the major species generated from the DME pyrolysis (e.g., $\mathrm{CH}_{2} \mathrm{O}, \mathrm{CO}$, and $\mathrm{H}_{2}$ ) increase at the fuel tube exit with decreasing $U_{0}$, which indicates the increase of the degree of DME pyrolysis within the fuel tube.

It is also readily observed that for high $U_{0}$, the mass fraction of $\mathrm{CH}_{2} \mathrm{O}$ first decreases immediately after issuing from the fuel tube exit and then, it starts to increase again, exhibiting its maximum value near the flamebase [10]. Meanwhile, the mass fractions of CO and $\mathrm{H}_{2}$ increase rapidly right after the $\mathrm{CH}_{2} \mathrm{O}$ increase. This is because $\mathrm{CH}_{2} \mathrm{O}$ is an intermediate product of DME pyrolysis, while $\mathrm{CH}_{4}, \mathrm{CO}$, and $\mathrm{H}_{2}$ are its final products as shown in Fig. 3. These characteristics also indicate that the DME jet is continuously decomposed into the small species even within the burner, especially right upstream of the flamebase where the thermal ignition process occurs. However, the mass fraction of $\mathrm{H}_{2}$ near the flamebase rapidly decreases with decreasing $U_{0}$ although the initial amount of $\mathrm{H}_{2}$ at the fuel tube exit 

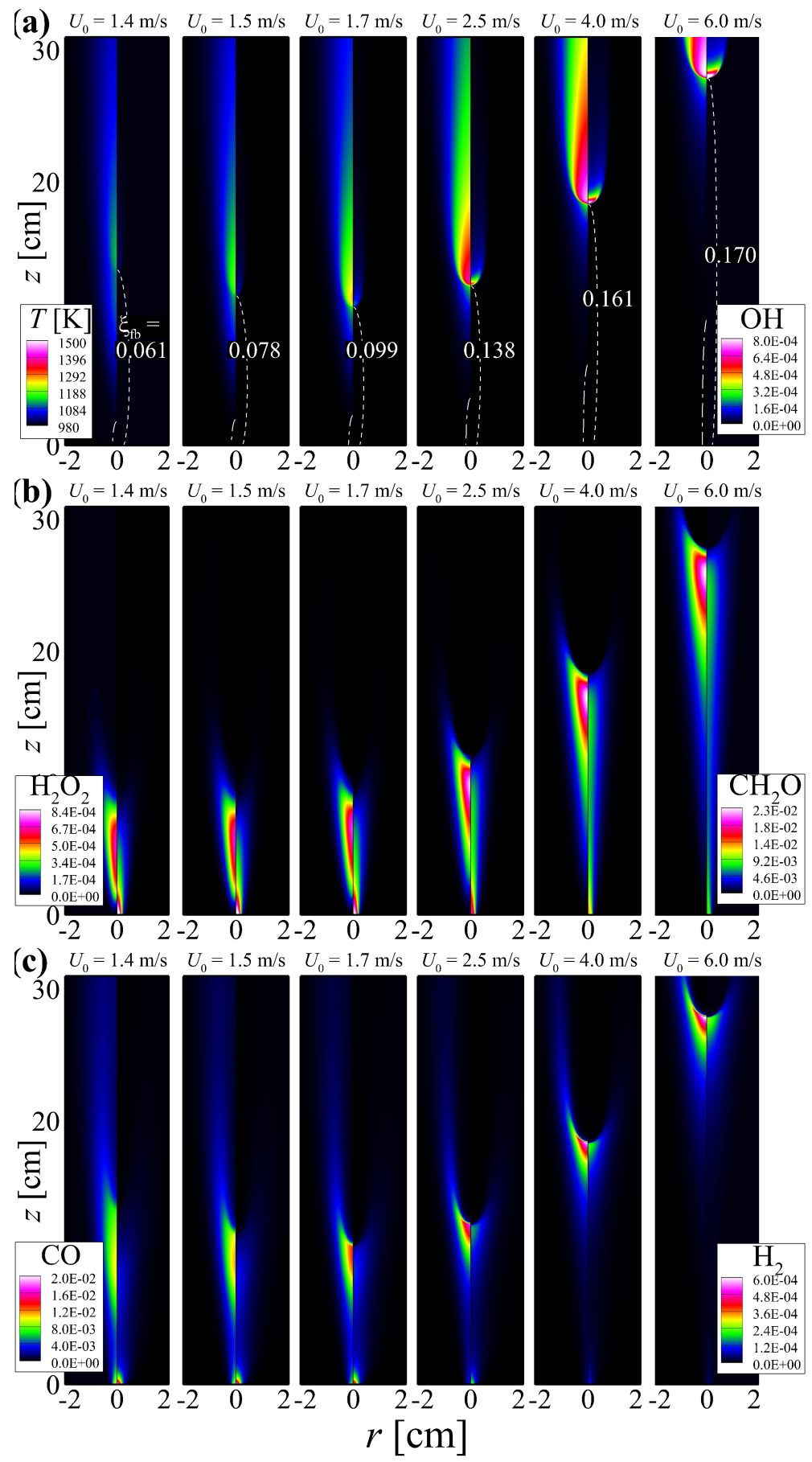

Figure 4: Isocontours of (a) $T$ (left half) and $Y_{\mathrm{OH}}$ (right half), (b) $Y_{\mathrm{H}_{2} \mathrm{O}_{2}}$ (left half) and $Y_{\mathrm{CH}_{2} \mathrm{O}}$ (right half), and (c) $Y_{\mathrm{CO}}$ (left half) and $Y_{\mathrm{H}_{2}}$ (right half) for autoignited laminar lifted DME jet flames for various $U_{0}$ with $T_{0}=980 \mathrm{~K}$ and $X_{\mathrm{F}, 0}=0.08$. The dashed and dash-dot lines in (a) represent the mixture fraction isoline passing through the flamebase, $\xi_{\mathrm{fb}}$, and the stoichiometric mixture fraction isoline, $\xi_{\mathrm{st}}=0.472$, respectively. 
is much higher at low $U_{0}$ than that at high $U_{0}$. This implies that small species generated by DME pyrolysis are more likely to diffuse out radially-outward with decreasing $U_{0}$ due to their fast diffusion rate.

To compare the numerical results with those of experiments from [10], Fig. 5 shows both $H_{\mathrm{L}}$ variations as a function of $U_{0}$ together with $\left(T_{\max }-T_{0}\right) / T_{\mathrm{ig}}$ and $\tau_{\mathrm{ig}, \mathrm{st}}$. Here, $H_{\mathrm{L}}$ is defined as the axial length from the fuel tube exit to the flamebase. Several points are noted from the figure. First, although the present numerical simulations adopt $T_{0}$ larger than that of the experiments, they qualitatively reproduce the U-shaped $H_{\mathrm{L}}$ trend of the experiments: $H_{\mathrm{L}}$ increases with increasing $U_{0}$ under relatively-high $U_{0}$ conditions (i.e., $U_{0}>1.7 \mathrm{~m} / \mathrm{s}$ ), $H_{\mathrm{L}}$ decreases with increasing $U_{0}$ under relatively-low $U_{0}$ conditions (i.e., $U_{0} \leq 1.7 \mathrm{~m} / \mathrm{s}$ ). As $U_{0}$ decreases further (i.e., $U_{0}<1.4 \mathrm{~m} / \mathrm{s}$ ), the DME fuel jet fails to autoignite due to the increase of fuel and temperature diffusion toward the coflow air. Second, $\left(T_{\max }-T_{0}\right) / T_{\mathrm{ig}}$ is found to be much lower than unity, which confirms that all the lifted flames satisfy the criteria selected to identify MILD combustion. Third, $\tau_{\mathrm{ig}, \mathrm{st}}$, which is evaluated from the fuel mixture at the fuel jet exit, increases with increasing $U_{0}$ such that the conventional $H_{\mathrm{L}}\left(\sim Y_{\mathrm{F}, 0} U_{0} \tau_{\text {ig,st }}^{2}\right)$ correlation [7] for autoignited laminar lifted flames can predict only a monotonic increase in $H_{\mathrm{L}}$ with increasing $U_{0}$. Therefore, the decreasing $H_{\mathrm{L}}$ behavior under relatively-low $U_{0}$ conditions cannot be solely explained by the conventional $H_{\mathrm{L}}$ correlation even though the DME pyrolysis effect is already incorporated in $\tau_{\mathrm{ig}, \mathrm{st}}$.

\subsection{Differential diffusion effect}

Instead of the effect of DME pyrolysis, we conjecture that the fast diffusion rate of small species generated from the pyrolysis of DME may induce the U-shaped $H_{\mathrm{L}}$ behavior as demonstrated in our previous study on the binary fuel mixture of $\mathrm{CH}_{4} / \mathrm{H}_{2}$ [11]. This is because the slower the fuel jet is, the more small species such as $\mathrm{H}_{2}$ is produced from the DME pyrolysis (see Fig. 3). Moreover, the differential diffusion effect becomes more prominent for relatively-low $U_{0}$ because the small species can have longer time to diffuse out from the fuel jet. Since the mass diffusivity of hydrogen, $D_{\mathrm{H}_{2}}$, exhibits the largest value among the major species generated from the DME pyrolysis, additional simulations 

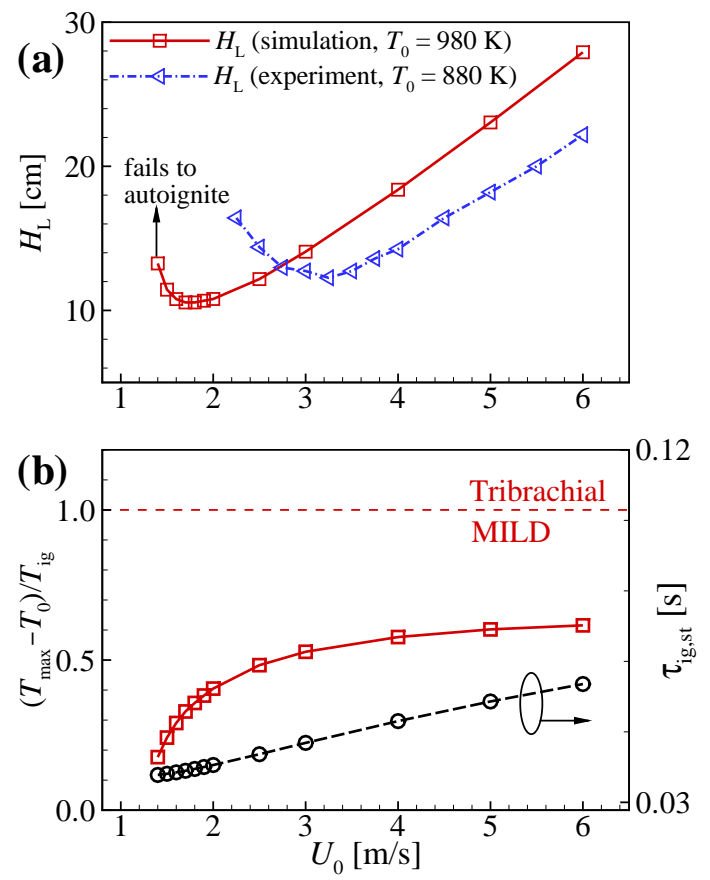

Figure 5: Variations of (a) $H_{\mathrm{L}}$ and (b) $\left(T_{\max }-T_{0}\right) / T_{\mathrm{ig}}$ and $\tau_{\mathrm{ig}, \text { st }}$ as a function of $U_{0}$ for the autoignited laminar lifted DME jet with $T_{0}=980$ and $X_{\mathrm{F}, 0}=0.08$.

are performed by setting $D_{\mathrm{H}_{2}}$ to that of DME, $D_{\mathrm{DME}}$, to test the differential diffusion effect on $H_{\mathrm{L}}$.

Figure 6 shows the isocontours of temperature and mass fractions of $\mathrm{OH}, \mathrm{H}_{2}$, and $\mathrm{H}_{2} \mathrm{O}_{2}$ of autoignited laminar lifted DME jet flames with modified $D_{\mathrm{H}_{2}}$ under the same conditions as in Fig. 4: i.e., $T_{0}=980 \mathrm{~K}$ and $X_{\mathrm{F}, 0}=0.08$. It is readily observed from $\mathrm{OH}$ and $\mathrm{H}_{2}$ isocontours that $H_{\mathrm{L}}$ increases monotonically with $U_{0}$. Thus, the lifted flames do not exhibit the U-shaped $H_{\mathrm{L}}$ behavior any more, which verifies that the U-shaped $H_{\mathrm{L}}$ behavior of the DME jet flames is primarily attributed to the differential diffusion effect between the species generated from the DME pyrolysis through the fuel tube, especially to the fast diffusion rate of hydrogen.

To further identify the liftoff characteristics of both cases, Fig. 7 shows the variations of $H_{\mathrm{L}}$ and $\left(T_{\max }-T_{0}\right) / T_{\text {ig }}$ as a function of $U_{0}$ for the normal and modified $D_{\mathrm{H}_{2}}$ cases. Two points are noted from Fig. 7. First, it is readily observed that the difference of $H_{\mathrm{L}}$ between the two 

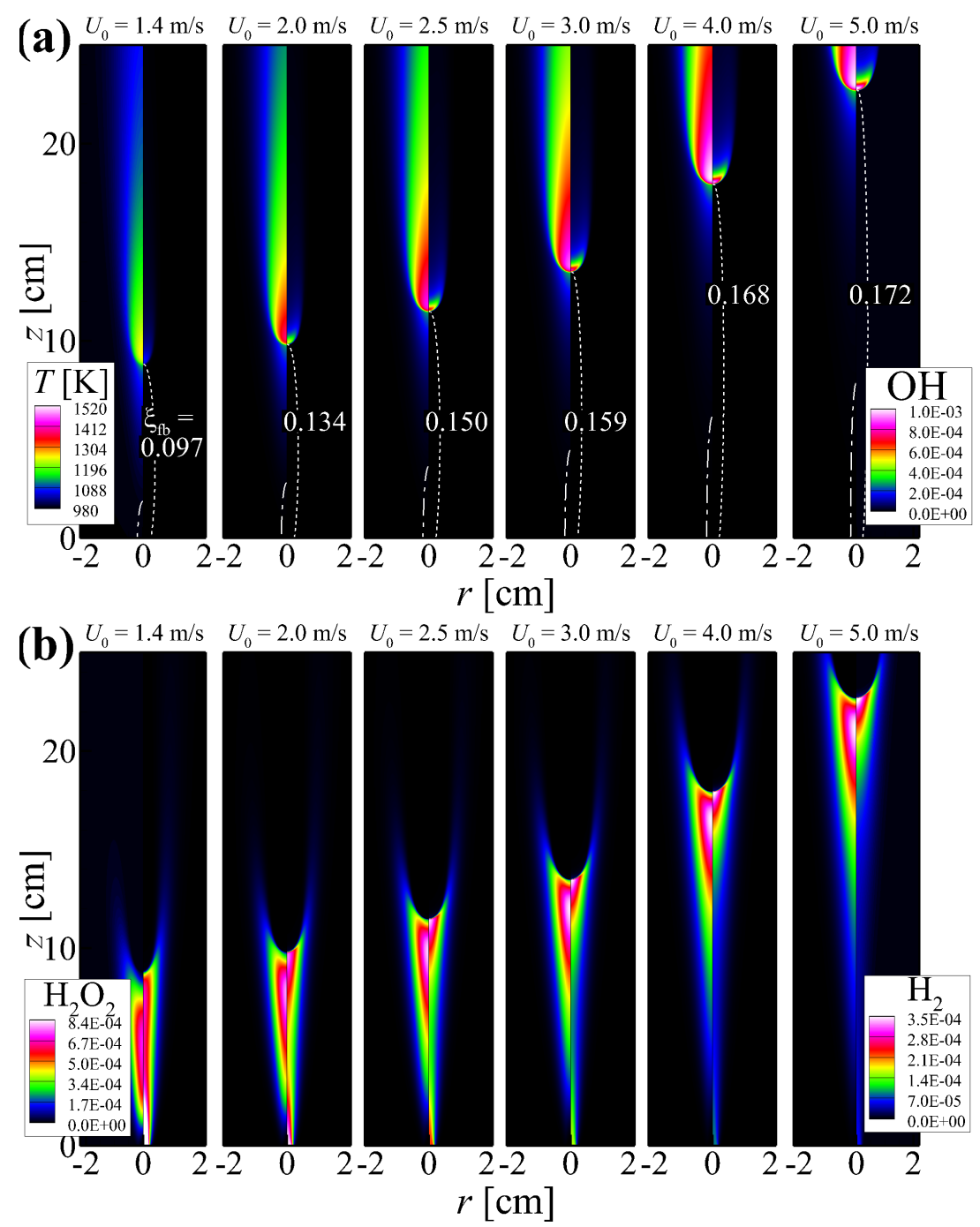

Figure 6: Isocontours of (a) $T$ (left half) and $Y_{\mathrm{OH}}$ (right half) and (b) $Y_{\mathrm{H}_{2} \mathrm{O}_{2}}$ (left half) and $Y_{\mathrm{H}_{2}}$ (right half) for autoignited laminar lifted DME jet flames with modified $D_{\mathrm{H}_{2}}$ for various $U_{0}$ with $T_{0}=980 \mathrm{~K}$ and $X_{\mathrm{F}, 0}$ $=0.08$. The dashed and dash-dot lines in (a) represent the mixture fraction isoline passing through the flamebase, $\xi_{\mathrm{fb}}$, and the stoichiometric mixture fraction isoline, $\xi_{\mathrm{st}}=0.472$, respectively. 

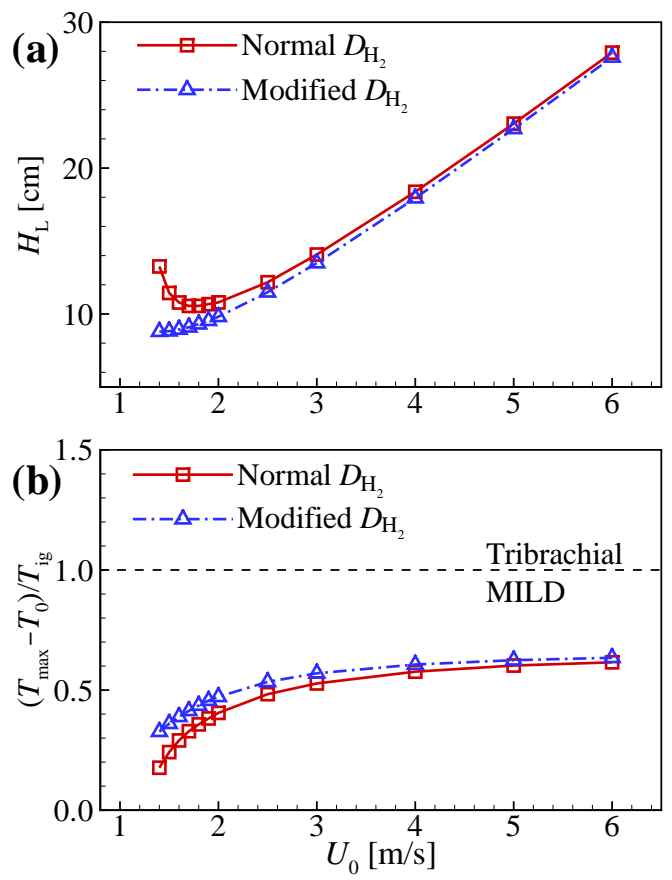

Figure 7: Variations of (a) $H_{\mathrm{L}}$ and (b) $\left(T_{\max }-T_{0}\right) / T_{\mathrm{ig}}$ as a function of $U_{0}$ for the normal and modified $D_{\mathrm{H}_{2}}$ cases with $T_{0}=980 \mathrm{~K}$ and $X_{\mathrm{F}, 0}=0.08$.

cases becomes significant for relatively-small $U_{0}$, while it becomes negligible for relativelylarge $U_{0}$. As mentioned above, the degree of DME pyrolysis and the resultant differential diffusion effect become significant for relatively-small $U_{0}$, and hence, $H_{\mathrm{L}}$ show such large difference for relatively-small $U_{0}$. Second, for relatively-small $U_{0},\left(T_{\max }-T_{0}\right) / T_{\text {ig }}$ also shows a large disparity, which becomes negligible for relatively-large $U_{0}$. For the modified $D_{\mathrm{H}_{2}}$ case, the radially-outward diffusion of $\mathrm{H}_{2}$ from the center of the fuel jet, which is originally generated from the DME pyrolysis, is significantly suppressed due to small modified $D_{\mathrm{H}_{2}}$ (see Fig. 6b), and consequently, the mixture fraction at the flamebase, $\xi_{\mathrm{fb}}$, exhibits slightly larger value than that of the corresponding normal $D_{\mathrm{H}_{2}}$ case (see Figs. 4 and 7 ), which leads to the increase of $T_{\max }$ for the modified $D_{\mathrm{H}_{2}}$ case.

It is also of importance to note that even if other high-hydrocarbon fuels such as $n$ heptane and iso-octane can be decomposed under high temperature conditions, they would not exhibit a U-shaped $H_{\mathrm{L}}$ behavior under MILD combustion condition as in [40, 41]. We 
performed 0-D simulation of $n$-heptane pyrolysis at $T_{0}$ and $X_{\mathrm{F}, 0}$ (not shown here), which revealed that the overall pyrolysis process of DME is much faster than that of $n$-heptane. Furthermore, the main products of DME pyrolysis are small species such as $\mathrm{CH}_{4}, \mathrm{CO}$, and $\mathrm{H}_{2}$, while $n$-heptane pyrolysis produces relatively-large species such as $\mathrm{C}_{2} \mathrm{H}_{4}$. This result implies that much higher $T_{0}$ is required to amplify the pyrolysis effect of $n$-heptane; however, autoignited laminar lifted $n$-heptane jet flames would not exhibit under such high temperature because they might be attached to the jet nozzle. We believe that the differential diffusion effect induced by DME pyrolysis is the primary reason for the U-shaped $H_{\mathrm{L}}$ behavior which is, therefore, a unique feature of autoignited lifted DME jet flames under MILD combustion condition.

\section{Flame stabilization and autoignition characteristics}

In the previous section, we investigated the U-shaped $H_{\mathrm{L}}$ behavior of autoignited DME lifted jet flames and found that the fast diffusion rate of hydrogen generated from the DME pyrolysis mainly attributes to such $H_{\mathrm{L}}$ behavior. In this section, we elucidate the flame stabilization mechanisms of autoignited laminar lifted jet flames for the decreasing/increasing $H_{\mathrm{L}}$ regimes by adopting the species transport budget, flame speed, and chemical explosive mode analyses.

\subsection{Stabilization mechanisms}

The species transport budget analysis has been widely adopted to elucidate the stabilization mechanisms of autoignited lifted jet flames [11, 12, 42, 43]. In a steady state, the convection $(\mathbf{C})$, diffusion $(\mathbf{D})$, and reaction $(\mathbf{R})$ terms of a species equation balance one another. Instead of $\mathbf{D}$ itself, we use its decomposed components such as parallel $\mathbf{D}_{s}$ and perpendicular $\mathbf{D}_{t}$ to the streamline to identify flame back diffusion by $\mathbf{D}_{s}$ and transverse stratification by $\mathbf{D}_{t}$. Note that in the reaction zone of a typical premixed flame, $\mathbf{D}_{s}$ and $\mathbf{R}$ terms balance each other while $\mathbf{C}$ is negligibly small. In an inhomogeneous autoignition process, however, $\mathbf{C}$ and $\mathbf{R}$ terms balance each other with negligible $\mathbf{D}_{s}$ [12]. In some cases including autoignited jet flames stabilized by "autoignition-assisted flame propagation", C, 

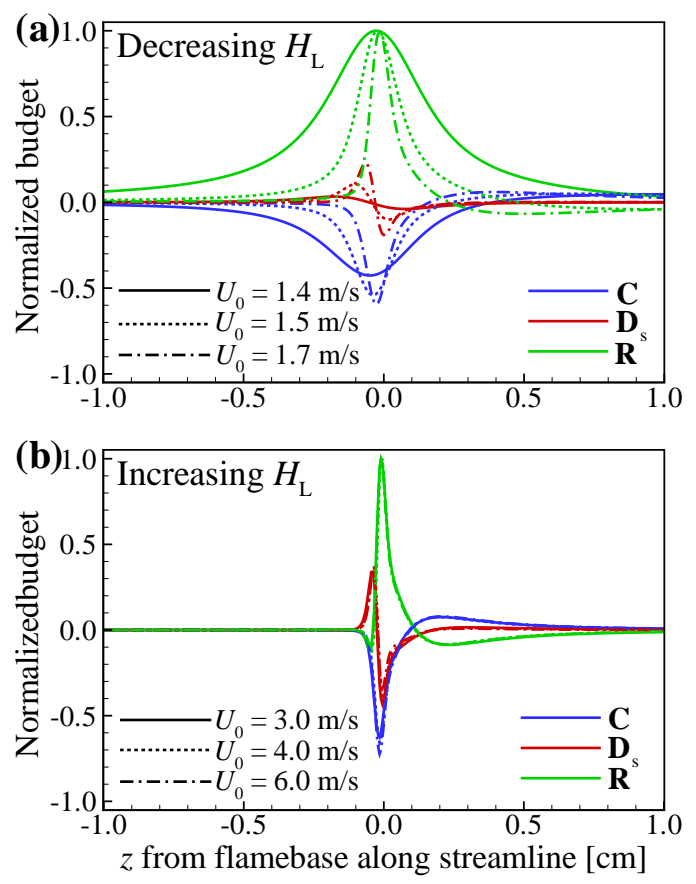

Figure 8: Profiles of convection $(\mathbf{C})$, flame back diffusion $\left(\mathbf{D}_{s}\right)$, and chemical reaction $(\mathbf{R})$ terms along the streamline passing through the flamebase for (a) the decreasing $H_{\mathrm{L}}$, and (b) the increasing $H_{\mathrm{L}}$ regimes.

$\mathbf{D}_{s}$, and $\mathbf{R}$ terms can balance one another. For such an autoignited lifted jet flame, its liftoff height is determined by the balance between the flame propagation speed and the local flow velocity at the flamebase while the flame propagation speed is enhanced by thermal ignition process upstream of the flamebase [11-13, 44, 45].

Figure 8 shows the profiles of $\mathbf{C}, \mathbf{D}_{s}$, and $\mathbf{R}$ along the streamline passing through the flamebase for the decreasing and increasing $H_{\mathrm{L}}$ regimes. In the present study, we adopt hydroxyl radical $(\mathrm{OH})$ for the transport budget analysis because it is one of the representative flame markers in hydrocarbon fuel jet flames. In addition, we normalize the budget terms by the maximum absolute value of $\mathbf{R}$ for each $U_{0}$ case to qualitatively compare the flame characteristics with $U_{0}$.

For the increasing $H_{\mathrm{L}}$ regime $\left(3 \leq U_{0} \leq 6 \mathrm{~m} / \mathrm{s}\right)$ in Fig. $8 \mathrm{~b}, \mathbf{C}^{-} \mathbf{D}_{s}-\mathbf{R}$ balance is achieved at the flamebase, which implies that the autoignited lifted jet flames within this regime are stabilized by the autoignition-assisted flame propagation mode. Although $\mathbf{C} / \mathbf{D}_{s}$ slightly 
increases/decreases with increasing $U_{0}$, the overall flame structure such as the flame thickness and the contribution of each term to the species equation is nearly identical to each other regardless of $U_{0}$.

For the decreasing $H_{\mathrm{L}}$ regime $\left(1.4 \leq U_{0} \leq 1.7 \mathrm{~m} / \mathrm{s}\right)$ in Fig. 8a, however, the species transport budgets exhibit distinct features compared to those of the increasing $H_{\mathrm{L}}$ regime. First, the relative importance of $\mathbf{D}_{s}$ in the species equation significantly decreases with decreasing $U_{0}$, and ultimately $\mathbf{D}_{s}$ nearly vanishes for $U_{0}=1.4 \mathrm{~m} / \mathrm{s}$ case. Therefore, $\mathbf{C}-\mathbf{R}$ balance becomes predominant for the decreasing $H_{\mathrm{L}}$ regime. Second, the flame thickness significantly increases with decreasing $U_{0}$. These results demonstrate that the stabilization mechanism for the decreasing $H_{\mathrm{L}}$ regime gradually changes to the autoignition mode as $U_{0}$ decreases. It is of interest to note that in our previous study [11], the decreasing $H_{\mathrm{L}}$ behavior of autoignited laminar lifted methane/hydrogen jet flames occurs due to the flame mode change from the MILD combustion to the tribrachial edge flame by the fast diffusion rate of hydrogen. In the present study, however, the decreasing $H_{\mathrm{L}}$ behavior occurs for autoignited lifted jet flames with MILD combustion only, of which stabilization mechanism seems to change from autoignition to autoignition-assisted flame propagation mode with increasing $U_{0}$.

To further identify the stabilization mechanisms of the lifted jet flames, we perform the displacement speed analysis by evaluating the ratio of the propagation speed of autoignited lifted DME jet flames, $S_{\mathrm{e}}$, to the corresponding reference flame speed, $S_{\mathrm{R}}[13]$. Since $S_{\mathrm{R}}$ is the flame propagation speed of a 1-D unstrained laminar premixed flame, $S_{\mathrm{e}}$ would be comparable to the corresponding $S_{\mathrm{R}}$ when the lifted flames are stabilized by the flame propagation mode. On the other hand, $S_{\mathrm{e}}$ would be much faster than $S_{\mathrm{R}}$ if the lifted flames are mainly stabilized by autoignition $[11,46]$. To estimate $S_{\mathrm{e}}$ and $S_{\mathrm{R}}$, we adopt the densityweight displacement speed, $S_{\mathrm{d}}^{*}$, which is defined by [47-49],

$$
S_{\mathrm{d}}^{*}=\frac{1}{\rho_{u}\left|\nabla Y_{k}\right|}\left(\omega_{k}-\frac{\partial}{\partial x_{j}}\left(\rho Y_{k} V_{k, j}\right)\right)
$$


where $Y_{k}$ is the mass fraction, $V_{k, j}$ the diffusion velocity in the $j$-direction, $\omega_{k}$ the net production rate of species $k$, and $\rho_{\mathrm{u}}$ is the density of the unburnt mixture. $S_{\mathrm{d}}^{*}$ has been widely used to estimate the propagation speeds of reaction fronts $[3,4,42,50-52]$. Here, we adopt $\mathrm{OH}$ for the evaluation of $S_{\mathrm{d}}^{*}$. Note that $S_{\mathrm{d}}^{*}$ represents the relative displacement speed of the isocontours such that we can estimate $S_{\mathrm{e}}$ by evaluating $S_{\mathrm{d}}^{*}$ at the flamebase of the lifted flames.

In the present study, $S_{\mathrm{R}}$ upstream of the flamebase is estimated from 1-D transient reactive simulations as in $[11,42,51,53]$. Since the autoignition process is underway upstream of the flamebase, it is not straightforward to determine the initial mixture conditions for the 1-D $S_{\mathrm{R}}$ calculations. By observing that the flamebase for each case usually lies in the middle of the flame thickness, we specified them as the mixture conditions at a half flame thickness, $\delta_{\mathrm{f}} / 2$, upstream of the flamebase along the streamline passing through the flamebase. The simulations started with a high-temperature ignition source in the middle of the 1-D domain, and consequently, two combustion waves developed from the ignition source propagate into the initial reactive mixture ahead of them. The mixture upstream of the combustion waves is reactive but it would not autoignite till $\tau_{\mathrm{ig}}^{0}$. Therefore, the propagation speed of the combustion wave, $S_{\mathrm{d}}^{*}$, can be regarded as the laminar burning velocity, $S_{\mathrm{R}}$, similar to that in the diffusive limit in previous studies $[42,51,53]$. The obtained $S_{\mathrm{R}}$ is then compared to the $S_{\mathrm{e}}$ of the corresponding lifted flames. Note that only major species upstream of the flamebase such as DME, $\mathrm{CH}_{4}, \mathrm{H}_{2} \mathrm{O}$, etc. are taken into account in the initial mixture conditions of $S_{\mathrm{R}}$ calculations to prevent any occurrence of autoignition during the early stage of the simulations. We also examine how much $S_{\mathrm{R}}$ varies within the flame thickness by varying its evaluation location from $\left(\delta_{\mathrm{f}} / 2\right) \times 0.8$ to $\left(\delta_{\mathrm{f}} / 2\right) \times 1.2$ upstream of the flamebase (see supplementary material). The result demonstrates that $S_{\mathrm{R}}$ does not change much with the location for its evaluation.

Figure 9 shows the variations of $S_{\mathrm{R}}$ and $S_{\mathrm{e}} / S_{\mathrm{R}}$ for the decreasing and increasing $H_{\mathrm{L}}$ regimes. It is readily observed from the figure that $S_{\mathrm{e}} / S_{\mathrm{R}}$ exhibits nearly unity for the increasing $H_{\mathrm{L}}$ regime, demonstrating that the autoignited lifted flames within this regime are stabilized by the flame propagation mode. However, it is of importance to note that 


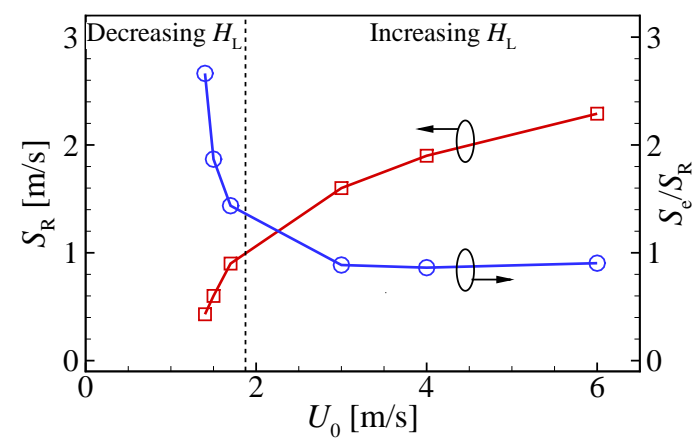

Figure 9: Variations of $S_{\mathrm{e}} / S_{\mathrm{R}}$ (blue) and $S_{\mathrm{R}}$ (red) at $\delta_{\mathrm{f}} / 2$ upstream of the flamebase along the streamline passing through the flamebase for various $U_{0}$ cases.

autoignition also plays a major role in stabilizing the flames even for these cases because the thermal ignition of the DME jet is in progress upstream of the flamebase, leading to temperature increase upstream of the flamebase. Figure 10 shows the temperature profiles at the upstream of the flamebase along the streamline passing through the flamebase, which shows that temperature increases from $T_{0}(=980 \mathrm{~K})$ at the upstream of the flamebase. Consequently, $S_{\mathrm{e}}$ is considerably enhanced by the temperature increase compared to that of the non-autoignited flames, and the lifted flames can be stabilized by the kinematic balance between the local flow velocity and the propagation speed of the flamebase, which is called by "autoignition-assisted flame propagation" [13, 54].

For the decreasing $H_{\mathrm{L}}$ regime with $U_{0}$, however, $S_{\mathrm{e}} / S_{\mathrm{R}}$ is above unity and decreases with increasing $U_{0}$, which indicates that the effect of autoignition on the flame stabilization becomes more significant for lower $U_{0}$. In this regime, relatively-small species such as $\mathrm{H}_{2}$ generated from the DME pyrolysis have more time to radially diffuse out from the flame region with decreasing $U_{0}$, which renders the mixture at the flamebase to be leaner with decreasing $U_{0}$. As a result, local temperature upstream of the flamebase decreases with decreasing $U_{0}$ as shown in Fig. 10a. Consequently, $S_{\mathrm{R}}$ also decreases significantly with decreasing $U_{0}$ as shown in Fig. 9. To overcome the upcoming local flow velocity, the autoignited lifted flames become more dependent on the ignition front speed, $S_{\mathrm{ig}} \sim 1 /\left|\nabla \tau_{\mathrm{ig}}\right|$, which is much faster 

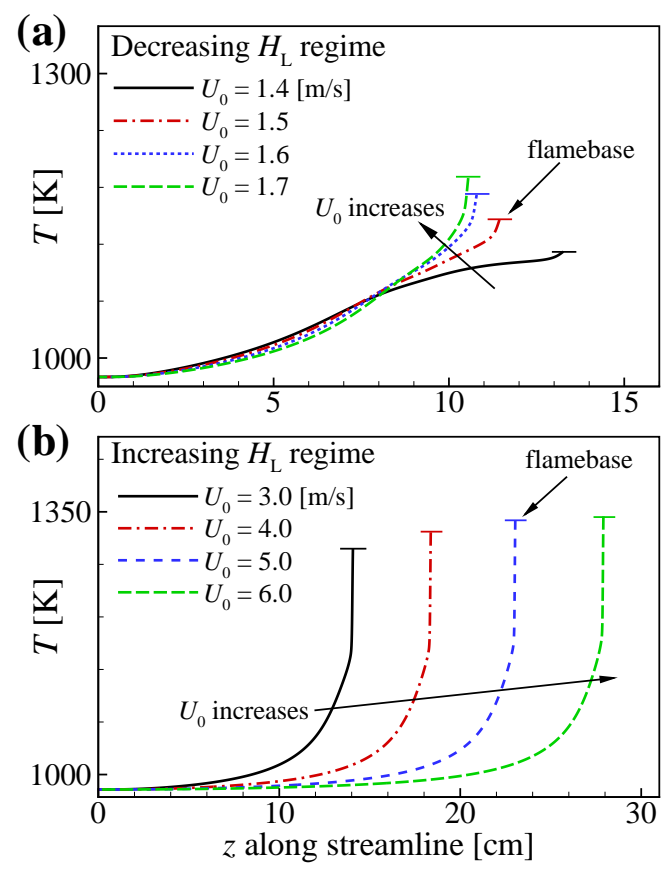

Figure 10: The profiles of temperature along the streamline passing through the flamebase for (a) the decreasing $H_{\mathrm{L}}$ regime and (b) the increasing $H_{\mathrm{L}}$ regime.

than $S_{\mathrm{R}}$ near the ignition kernels [46]. These results demonstrate that the stabilization mechanism of the autoignited lifted DME jet flames changes from the autoignition to the autoignition-assisted flame propagation mode for the decreasing $H_{\mathrm{L}}$ regime due to the fast diffusion of hydrogen produced from the DME pyrolysis, which is consistent with the result of the transport budget analysis.

As mentioned previously, the decreasing $H_{\mathrm{L}}$ behavior for $\mathrm{CH}_{4} / \mathrm{H}_{2}$ mixture flames occurs by the stabilization mechanism changes from the autoignition to the autoignition-assisted flame propagation mode, along with the flame regime change from the MILD combustion to the tribrachial edge flame regime [11]. In the present DME flames, the decreasing $H_{\mathrm{L}}$ behavior can be explained by the stabilization mechanism change from autoignition to autoignition-assisted flame propagation mode in only the MILD combustion regime. These results imply that the decreasing $H_{\mathrm{L}}$ behavior can occur by the transition of the stabilization mechanism from the autoignition to the autoignition-assisted flame propagation mode regardless of the flame regime change. 
(a) Decreasing $H_{\mathrm{L}}$ regime

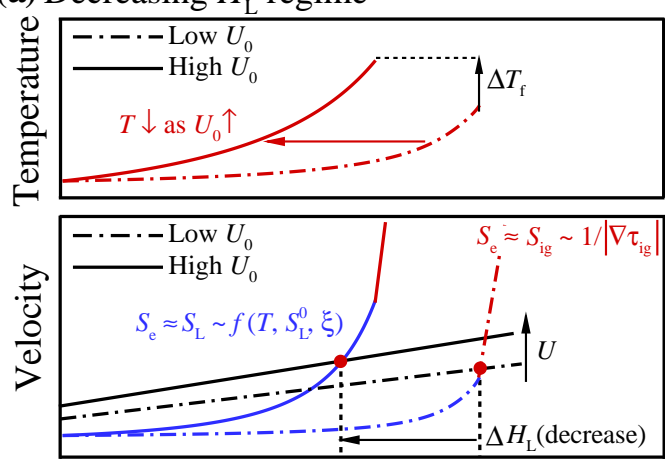

$z$ along streamline

(b) Increasing $H_{\mathrm{L}}$ regime

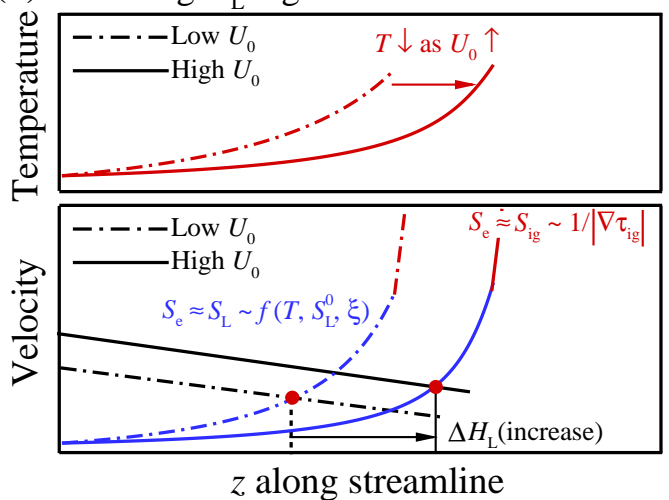

Figure 11: Schematic for the stabilization of autoignited laminar DME lifted flames with (a) decreasing $H_{\mathrm{L}}$ and (b) increasing $H_{\mathrm{L}}$ regimes.

To illustrate how the autoignited lifted flames are stabilized with $U_{0}$ and $H_{\mathrm{L}}$ is accordingly determined, a schematic of the $H_{\mathrm{L}}$ variation depending on the flow regimes is shown in Fig. 11. The axial velocity, $U$, increases with increasing $U_{0}$, while the overall profile along the streamline passing through the flamebase is found to be different depending on the decreasing/increasing $H_{\mathrm{L}}$ regimes. Since the autoignited laminar lifted flames are mainly stabilized by either the autoignition-assisted flame propagation or the autoignition mode, the propagation speed of the leading edge of the lifted flame, $S_{\mathrm{e}}$, features the reference laminar flame speed enhanced by ongoing temperature increase $\left(S_{\mathrm{R}}\right)$ for the former, or the spontaneous ignition front speed $\left(S_{\mathrm{ig}}\right)$ for the latter [46]. Therefore, the lifted flame can be stabilized where $S_{\mathrm{e}}$ balances $U$ as illustrated in Fig. 11 .

For the increasing $H_{\mathrm{L}}$ regime where the DME pyrolysis and resultant differential diffusion 
effects are negligible, the overall autoignition characteristics do not change much with $U_{0}$, and hence, the local temperature, $T$, and resultant $S_{\mathrm{e}}$ are just spatially elongated with increasing $U_{0}$ as shown in Figs. $10 \mathrm{~b}$ and $11 \mathrm{~b}$. As such, once $U_{0}$ increases, the lifted flame is stabilized further downstream than that with low $U_{0}$ as illustrated in Fig. 11b. In addition, the stabilization mechanism for the increasing $H_{\mathrm{L}}$ regime, or the conventional autoignited lifted flames with single fuel component, slowly changes from the autoignition-assisted flame propagation to the autoignition mode with the increase in $U_{0}$ as illustrated in Fig. 8b.

For the decreasing $H_{\mathrm{L}}$ regime where the pyrolysis of DME and resultant differential diffusion effect are significant, the overall temperature profile and resultant $S_{\mathrm{e}}$ of relativelyhigh $U_{0}$ move towards upstream compared to those of low $U_{0}$ due to spatially-enhanced ignition process as shown in Fig. 10a. This is because the radial diffusion of small species is more suppressed for high $U_{0}$, leading to the increase in $\xi$ and $T$ at the flamebase. As such, the lifted flame with high $U_{0}$ is stabilized further upstream than that with low $U_{0}$ as described in Fig. 11a. It is also interest to note that the flame temperature, $T_{\mathrm{f}}$, notably increases with increasing $U_{0}$, and thus, the corresponding $S_{\mathrm{R}}$ profile also dramatically changes. In this sense, the stabilization mechanism of the lifted flames with large differential diffusion effect is more sensitive to the $U_{0}$ variations as shown in Fig. 8a.

\subsection{Ignition characteristics based on CEMA}

To further understand how the fast diffusion rates of small species control the ignition characteristics of the autoignited lifted DME jet flames, we carry out the CEMA that has been widely adopted for many combustion problems including laminar/turbulent jet flames $[4,11,14,15,34,35,55,56]$ and various types of homogenous charge compression ignition (HCCI) combustion [36, 37, 57-61]. The CEMA is based on the Jacobian of the local chemical source term, $\mathbf{J}_{\omega}$, in the discretized conservation equations for a reacting flow. As mentioned earlier, the eigenvalue, $\lambda_{\mathrm{e}}$, can be defined by the eigenmode of the Jacobian as $\lambda_{\mathrm{e}}=\mathbf{b}_{e} \cdot \mathbf{J}_{\omega} \cdot \mathbf{a}_{e}$, where $\mathbf{a}_{e}$ and $\mathbf{b}_{e}$ are the pair of the left and right eigenvectors, respectively. A chemical explosive mode (CEM) is a chemical mode for which the real part of $\lambda_{\mathrm{e}}$ is positive, and hence, the local mixture is expected to autoignite unless there exist thermal and radical 
losses.

The normalized contributions of each variable and each reaction to a CEM are measured by evaluating the explosive index, EI, and the participation index, PI, which are defined by [35-37]:

$$
\begin{gathered}
\mathbf{E I}=\frac{\left|\mathbf{a}_{e} \otimes \mathbf{b}_{e}^{\mathrm{T}}\right|}{\sum\left|\mathbf{a}_{e} \otimes \mathbf{b}_{e}^{\mathrm{T}}\right|}, \\
\mathbf{P I}=\frac{\left|\left(\mathbf{b}_{e} \cdot \mathbf{S}\right) \otimes \mathbf{R}\right|}{\sum\left|\left(\mathbf{b}_{e} \cdot \mathbf{S}\right) \otimes \mathbf{R}\right|},
\end{gathered}
$$

where $\mathbf{S}$ and $\mathbf{R}$ represent the stoichiometric coefficient matrix and the net reaction rate vector, respectively. The symbol $\otimes$ denotes the element-wise multiplication of two vectors. Thus, the key variables and reactions contributing to the ignition can be identified by evaluating EI and PI. We perform the CEMA for cases with $U_{0}=1.5$ and $5.0 \mathrm{~m} / \mathrm{s}$ where the differential diffusion effect is significant and marginal to the autoignition, respectively. For comparison purposes, we also carry out the CEMA of the 0-D homogeneous ignition of the fuel/air mixture at the fuel jet exit for both cases, and as such, we can identify different ignition characteristics of the 0-D homogeneous reactor and the 2-D axisymmetric flame; the former does not include any mass transport while the latter takes into account different mass diffusion rates for each species.

Figure 12 shows the EI of important variables including temperature for the 0 -D ignition of DME/air mixtures and 2-D cases along the streamline passing through the flamebase. For 2-D simulation cases, we estimate $\tau_{\text {res }}$ by numerically integrating $\Delta s / U$ along the streamline passing through the flamebase. Note that we separate the ignition process into two stage: the "preheated stage" and the "thermal ignition stage". The former/latter represents a stage when the EI of temperature is smaller/larger than those of species.

Several points are noted from Figs. $12 \mathrm{a}$ and b. For the $0-\mathrm{D}$ case with $U_{0}=1.5 \mathrm{~m} / \mathrm{s}$ where the initial DME is highly decomposed into other species, the duration of the preheated stage is approximately two times shorter than that for the $0-\mathrm{D}$ case with $U_{0}=5 \mathrm{~m} / \mathrm{s}$ where the 
decomposition of the initial DME is negligible. However, the durations of the thermal ignition stage for two cases are nearly identical. This trend remains the same for different equivalence ratios (see the supplementary material). This implies that the main role of the degree of initial DME pyrolysis on the ignition is to reduce the preheated stage and advance the start of thermal ignition stage. Also note that the contribution of $\mathrm{H}_{2} \mathrm{O}_{2}$ to the CEM is the greatest among the species during the preheated stage, indicating that $\mathrm{H}_{2} \mathrm{O}_{2}$ plays a key role in this stage [62].

As shown in Figs. 12c and d, the duration of the preheated stage for the 2-D case with $U_{0}=1.5 \mathrm{~m} / \mathrm{s}$ is approximately two times shorter than that for $U_{0}=5.0 \mathrm{~m} / \mathrm{s}$ case, which is consistent with the 0-D results. However, the duration of the thermal ignition stage for the 2-D case with $U_{0}=1.5 \mathrm{~m} / \mathrm{s}$ is much longer than that for $2-\mathrm{D}$ case with $U_{0}=5.0 \mathrm{~m} / \mathrm{s}$ as well as that for $0-\mathrm{D}$ case with $U_{0}=1.5 \mathrm{~m} / \mathrm{s}$, implying that the differential diffusion effect extends the duration of the thermal ignition stage of the 2 -D case with $U_{0}=1.5 \mathrm{~m} / \mathrm{s}$. Moreover, the overall $\phi$ profile along the streamline for $U_{0}=1.5 \mathrm{~m} / \mathrm{s}$ case is much lower than that for $U_{0}=$ $5.0 \mathrm{~m} / \mathrm{s}$ case in the thermal ignition stage. This result substantiates that for 2-D case with $U_{0}=1.5 \mathrm{~m} / \mathrm{s}$, the increasing differential diffusion effect renders the mixture to be leaner, which eventually retards the autoignition process in the 2-D jet flames.

To further elucidate the contribution of each elementary reaction to the CEM of autoignited DME jet flames, the participation index (PI) of important reactions for the autoignition of DME flames for the same $0-\mathrm{D}$ and 2-D cases are shown in Fig. 13. From the 0-D ignition cases in Figs. 13a and b, we can identify the fundamental reaction pathways of the DME flames: the thermal decomposition of DME (R239-247) ( $\mathrm{R}$ is the reaction number in [18]), the conversion of $\mathrm{CH}_{2} \mathrm{O}$ to $\mathrm{H}_{2} \mathrm{O}_{2}$ through $\mathrm{CH}_{2} \mathrm{O}+\mathrm{HO}_{2} \rightarrow \mathrm{HCO}+\mathrm{H}_{2} \mathrm{O}_{2}(\mathrm{R} 46)$, the conversion of $\mathrm{CH}_{3}$ to $\mathrm{CH}_{3} \mathrm{O}$ to $\mathrm{CH}_{2} \mathrm{O}$ (R48-51, R71, R73-77), the chain branching of $\mathrm{H}_{2} \mathrm{O}_{2}$ through $\mathrm{H}_{2} \mathrm{O}_{2} \rightarrow \mathrm{OH}+\mathrm{OH}$ (R20), the chain branching of $\mathrm{H}_{2}$ through $\mathrm{H}+\mathrm{O}_{2} \rightarrow \mathrm{O}$ $+\mathrm{OH}(\mathrm{R} 1)$, and the $\mathrm{HO}_{2}$ formation through $\mathrm{H}+\mathrm{O}_{2} \rightarrow \mathrm{HO}_{2}(\mathrm{R} 13)$, and the final $\mathrm{CO}$ to $\mathrm{CO}_{2}$ conversion step (R29; not shown here) are sequentially and/or simultaneously observed 

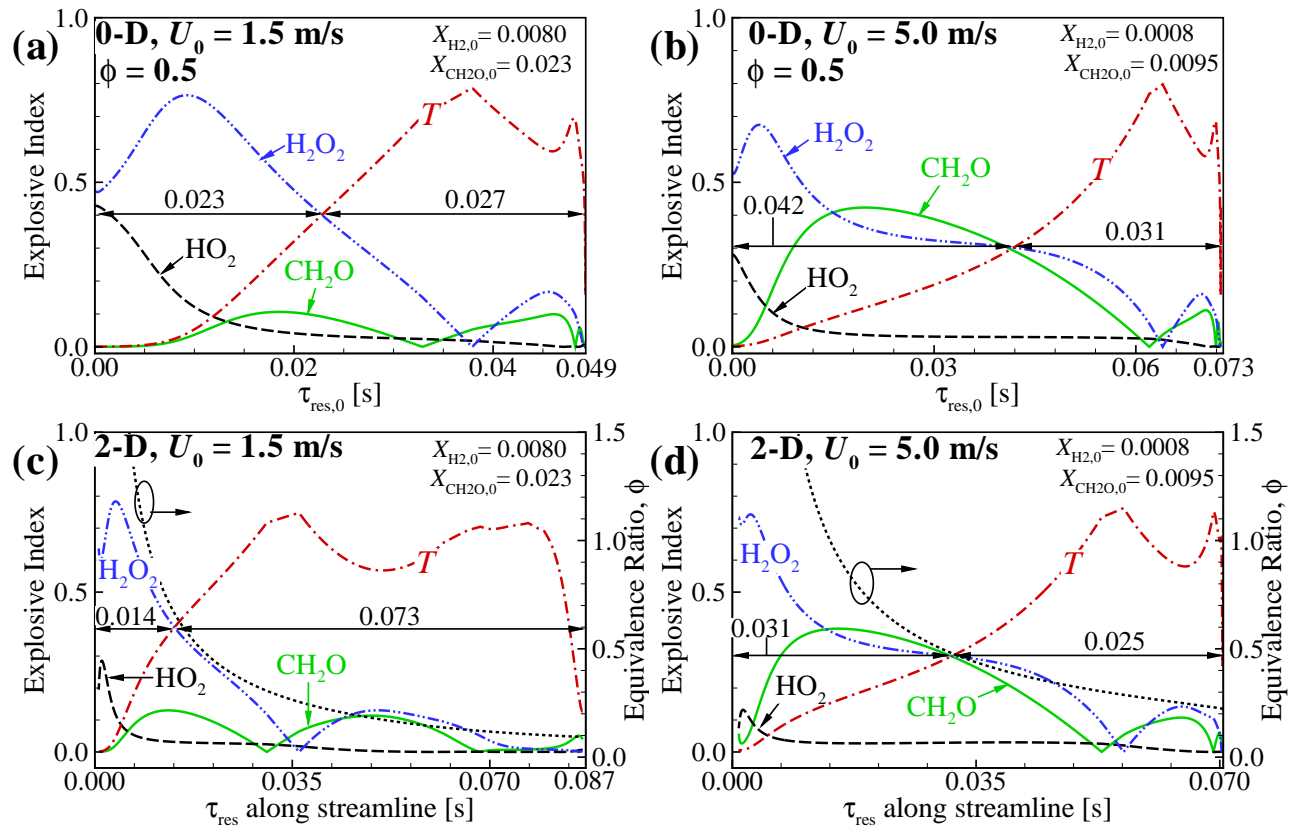

Figure 12: EI of important species and temperature for (top) 0-D homogeneous ignition of DME flames, and (bottom) autoignited laminar lifted DME jet flames along the streamline passing through the flame base. $U_{0}=$ (left) 1.5 and (right) $5.0 \mathrm{~m} / \mathrm{s}$ cases are selected to the analysis.

$[23,63,64]$.

During the preheated stage, the relative contributions of R46 and R20 to CEM increase as DME is more decomposed (i.e., $U_{0}=1.5 \mathrm{~m} / \mathrm{s}$ case). Therefore, the amount of $\mathrm{CH}_{2} \mathrm{O}$ produced by the initial DME pyrolysis plays an important role in generating $\mathrm{H}_{2} \mathrm{O}_{2}$ through R46, consequently leading to the thermal ignition by activating R20 that is one of the intermediate radical growth reactions in hydrocarbon oxidation. Since the mass diffusivities of $\mathrm{CH}_{2} \mathrm{O}$ and $\mathrm{H}_{2} \mathrm{O}_{2}$ are relatively small, the overall ignition behavior for 2-D cases at the preheated stage does not change much, thereby following the 0-D homogeneous ignition trend during the preheated stage.

During the thermal ignition stage, $T$ increases through R20 up to approximately $1050 \mathrm{~K}$ for 0-D cases (red vertical line in Figs. 13a and b), and then, the relative importance of R20 becomes decreasing, while the chain branching step of hydrogen (R1) start to contribute the most to the CEM [65] regardless of the initial $\phi$ (see supplementary materials). In addition, the contribution of $\mathrm{HO}_{2}$ formation step (R13) on the autoignition of DME is marginal for 

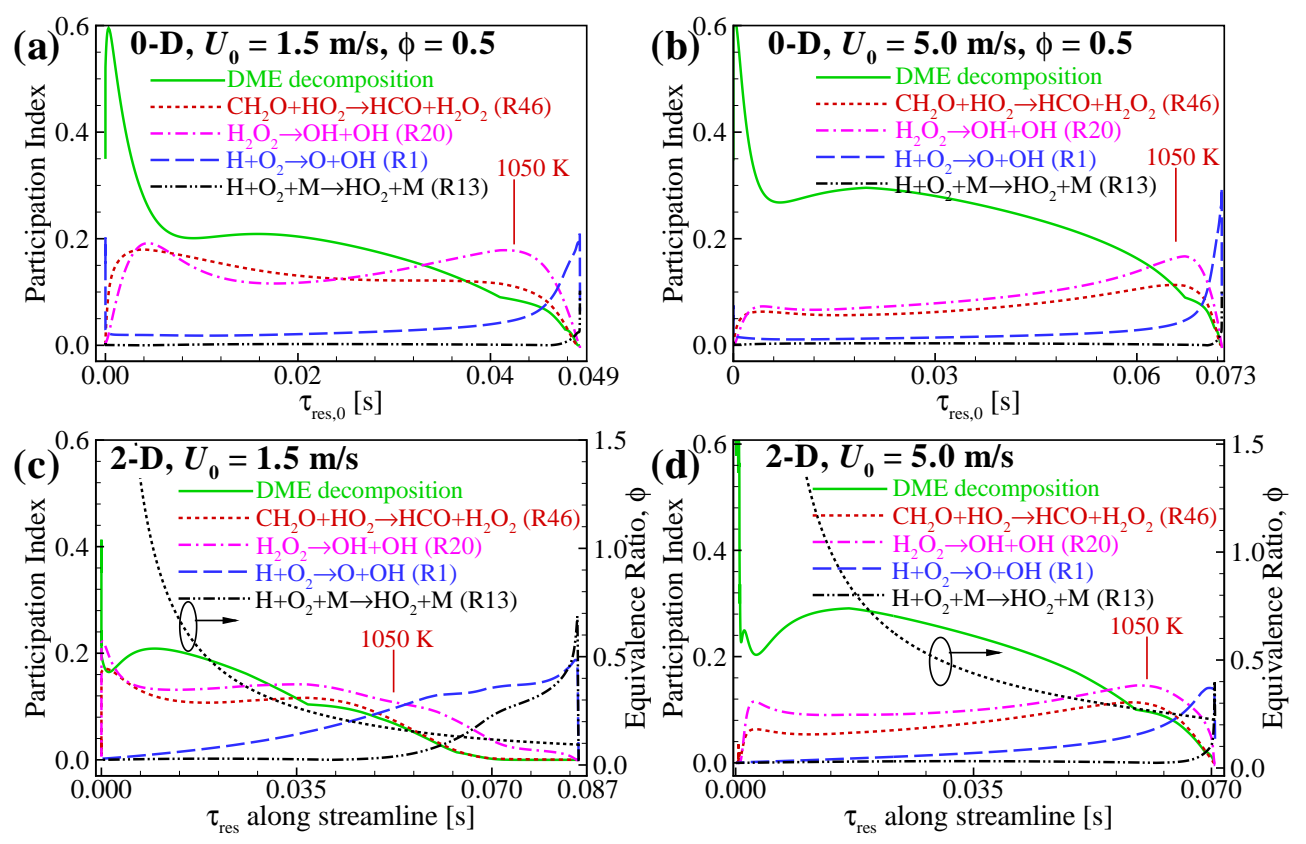

Figure 13: PI of various reactions for (top) 0-D homogeneous ignition of DME flames, and (bottom) autoignited laminar lifted DME jet flames along the streamline passing through the flame base. $U_{0}=($ left $) 1.5$ and (right) $5.0 \mathrm{~m} / \mathrm{s}$ cases are selected to the analysis. Red vertical line represents the time when $T$ reaches to $1050 \mathrm{~K}$. 
the relatively-high $\phi$, but R13 becomes important to the CEM when $\phi$ is 0.2 or lower as shown in the supplementary materials. This is because the rate of temperature increase is relatively low at lean conditions such that $\mathrm{R} 1$, an endothermic reaction, is not favored while R13, an exothermic step competitive to R1, starts to participate in the autoignition [66].

During the thermal-ignition stage for 2-D cases in Figs. 13c and d, it is readily observed that the autoignition process after $T>1050 \mathrm{~K}$ is significantly delayed for case with $U_{0}=$ $1.5 \mathrm{~m} / \mathrm{s}$, compared to the $0-\mathrm{D}$ cases as well as the $2-\mathrm{D}$ case with $U_{0}=5.0 \mathrm{~m} / \mathrm{s}$. It is of interest to note that the contribution of R13 to the CEM for case with $U_{0}=1.5 \mathrm{~m} / \mathrm{s}$ is much larger than that for case with $U_{0}=5 \mathrm{~m} / \mathrm{s}$. As mentioned above, this is attributed to the differential diffusion effect for case with $U_{0}=1.5 \mathrm{~m} / \mathrm{s}$; the small species generated from the pyrolysis can diffuse out more from the flame zone for the low $U_{0}$ case than the high $U_{0}$ case. Then, the overall $\phi$ profile along the streamline decreases more significantly for the low $U_{0}$ case, and consequently, the autoignition process driven by high temperature chemistry such as R1 is not that explosive, which significantly delays the thermal ignition process compared to that for high $U_{0}$ case. These results demonstrate that the variation of $\phi$ and resultant autoignition characteristics are very sensitive to $U_{0}$ for the decreasing $H_{\mathrm{L}}$ regime. For the increasing $H_{\mathrm{L}}$ regime, however, the differential diffusion effect on the overall ignition characteristics is not significant, and thus, they do not change much with $U_{0}$. Therefore, $H_{\mathrm{L}}$ increases with increasing $U_{0}$.

\section{Flame regime change by pyrolysis}

In the previous sections, we investigated the effects of the DME pyrolysis on the autoignited lifted flames. However, the degree of DME pyrolysis in the fuel tube is limited by the fuel tube length, $L_{\text {res }}$, of $0.75 \mathrm{~m}$. As shown in Fig. 3, the 0-D pyrolysis of the DME/nitrogen mixture does not reach its equilibrium even after $6 \mathrm{~s}$. Therefore, to figure out how much the degree of DME pyrolysis affects the liftoff characteristics of autoignited DME jet flames, we first simulate numerically three additional cases with different $L_{\text {res }}$ of 0 , $3.0 \mathrm{~m}$, and $\infty$ by varying the fuel jet velocity. $L_{\mathrm{res}}=0$ case represents a DME jet without pyrolysis such that mixture composition at the fuel tube exit is set to pure DME diluted 
with nitrogen. In addition, the fully developed flow boundary condition is applied at the fuel tube exit and the temperature of fuel tube exit is specified to $T_{0}$ of $980 \mathrm{~K}$. $L_{\text {res }}=\infty$ case denotes a fully-pyrolyzed DME fuel jet of which composition is obtained from the 0-D numerical simulation of DME pyrolysis as in Fig. 3. Note that the computational domain and boundary conditions of $L_{\text {res }}=\infty$ case are identical to those of $L_{\text {res }}=0$ case except for the fuel composition at the fuel tube exit.

Figure 14 shows the $H_{\mathrm{L}}$ variations of autoignited DME jet flames as a function of the fuel jet velocity at the inlet of the fuel tube, $U_{\mathrm{F}}$, for various $L_{\mathrm{res}}$. Since $U_{0}$ increases with $L_{\text {res }}$ due to the decrease of fuel mixture density by the DME pyrolysis, $H_{\mathrm{L}}$ variations are shown as a function of $U_{\mathrm{F}}$ for fair comparison. Several points are noted. First, for case with $L_{\text {res }}$ $=0, H_{\mathrm{L}}$ increases monotonically with increasing $U_{\mathrm{F}}$. Even if a certain degree of pyrolysis of the DME jet occurs along the jet within the burner, it is not high enough to induce a U-shaped $H_{\mathrm{L}}$ behavior. Second, for case with $L_{\mathrm{res}}=3.0 \mathrm{~m}$, the degree of DME pyrolysis and the resultant differential diffusion effect become more significant than those of the cases with $L_{\mathrm{res}}=0$ and $0.75 \mathrm{~m}$, thereby leading to a more distinct $\mathrm{U}$-shaped $H_{\mathrm{L}}$ behavior.

It is of interest to note that any attached flames are not observed for the cases with $L_{\text {res }}$ $=0,0.75$, and $3.0 \mathrm{~m}$. This is opposite to the behavior of conventional non-autoignited jet flames $[16,17]$ or 1-D premixed flames [13] that become attached to the fuel jet nozzle at low jet velocities. Since lifted flames with MILD combustion are located further downstream of the stoichiometric mixture fraction isoline, the overall diffusion timescale of fuel in the radial direction can be longer than that of conventional non-autoignited lifted flames for which the flamebase lies at the stoichiometric mixture fraction isoline. Therefore, as the fuel jet velocity decreases, small species can have longer time to diffuse out from the reaction zone of the lifted flame, which makes it weaker and even fail to autoignite.

Third, for the case with $L_{\text {res }}=\infty$ where the degree of DME pyrolysis is maximized, a lifted flame becomes attached to the fuel tube exit when $U_{\mathrm{F}}$ becomes larger than approximately $0.6 \mathrm{~m} / \mathrm{s}$. As shown in Fig. 3, we can expect that the overall characteristics of autoignited DME jet flames change from those of DME jet to those of $\mathrm{CH}_{4} / \mathrm{H}_{2} / \mathrm{CO}$ jet as the degree of DME pyrolysis increases with increasing $\tau_{\text {res }}$ or $L_{\text {res }}$. This fuel transition may 


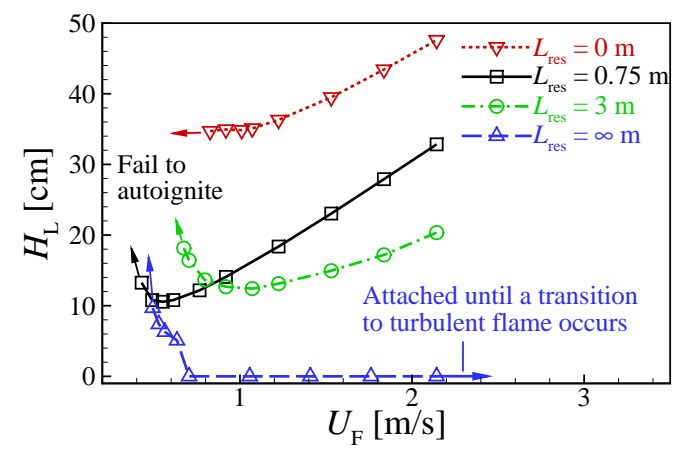

Figure 14: Variations of $H_{\mathrm{L}}$ as a function of $U_{\mathrm{F}}$ for the $L_{\mathrm{res}}=0,0.75,3$, and $\infty \mathrm{m}$ cases with $T_{0}=980 \mathrm{~K}$ and $X_{\mathrm{F}, 0}=0.08$.

significantly change its flame structure and liftoff characteristics. Note that the attached flame for $L_{\text {res }}=\infty$ is not lifted off by high $U_{\mathrm{F}}$ as far as the fuel jet is laminar.

To further identify the pyrolysis effect on the flame structure and liftoff characteristics, we vary $L_{\text {res }}$ from 0 to $23 \mathrm{~m}$ for $U_{\mathrm{F}}=1.53 \mathrm{~m} / \mathrm{s}$ this time. Figure 15 shows the isocontours of temperature and mass fractions of $\mathrm{OH}, \mathrm{HO}_{2}$, and $\mathrm{H}_{2} \mathrm{O}_{2}$ of autoignited laminar lifted DME jet flames for various fuel tube lengths at $T_{0}=980 \mathrm{~K}, X_{\mathrm{F}, 0}=0.08$, and $U_{\mathrm{F}}=1.53$ $\mathrm{m} / \mathrm{s}$. For these cases, the mean fuel jet velocity at the fuel tube exit, $U_{0}$, is found to vary from 5 to $6.3 \mathrm{~m} / \mathrm{s}$ with increasing $L_{\text {res }}$, which is inevitable due to the DME pyrolysis (see supplementary material). Nonetheless, we believe that the characteristics of autoignited jet flames with different $L_{\text {res }}$ are mainly affected by the fuel composition variation due to the DME pyrolysis rather than by $U_{0}$ change. This is because the liftoff height of the lifted flame keeps decreasing with increasing $L_{\text {res }}$ when $L_{\text {res }}>8 \mathrm{~m}$ and then, it becomes even attached to the burner in spite of relatively-large $U_{0}$ at large $L_{\text {res }}$ due to the DME pyrolysis.

It is readily observed from Fig. 15 that $H_{\mathrm{L}}$ shows a non-monotonic behavior with increasing $L_{\text {res }}$ while the flame structure changes from the lifted flame with MILD combustion to the lifted flame with tribrachial edge to the attached flame [11]. The degree of DME pyrolysis is increased with increasing $L_{\text {res }}$ while passing through the fuel tube, and consequently, approximately $16 \%$ and $93 \%$ amounts of the initial DME are decomposed into small species for cases with $L_{\text {res }}=0.75$ and $14 \mathrm{~m}$, respectively. In addition, the amount 
of $\mathrm{CH}_{2} \mathrm{O}$ generated from the pyrolysis is found to be maximized at $L_{\mathrm{res}}=5 \mathrm{~m}$ as can be expected from Fig. 3. Since the conversion of $\mathrm{CH}_{2} \mathrm{O}$ to $\mathrm{H}_{2} \mathrm{O}_{2}$ through $\mathrm{CH}_{2} \mathrm{O}+\mathrm{HO}_{2} \rightarrow \mathrm{HCO}$ $+\mathrm{H}_{2} \mathrm{O}_{2}$ (R46) occurs right after $\mathrm{CH}_{2} \mathrm{O}$ generation, we can observe more $\mathrm{H}_{2} \mathrm{O}_{2}$ upstream of the flamebase for small $L_{\text {res }}$ cases while the amounts of $\mathrm{CH}_{2} \mathrm{O}$ and $\mathrm{H}_{2} \mathrm{O}_{2}$ are marginal for large $L_{\text {res }}$ cases. All of these results imply that the flame structure change can be highly related to the change of fuel type from DME to $\mathrm{CH}_{4} / \mathrm{H}_{2} / \mathrm{CO}$ at the fuel tube exit.

To further identify the characteristics of the autoignited lifted jet flames with different $L_{\text {res }}$, the variations of $H_{\mathrm{L}}$ and $\left(T_{\max }-T_{0}\right) / T_{\mathrm{ig}}$ are shown in Fig. 16. The conventional $H_{\mathrm{L}}$ correlation for the autoignited laminar lifted jet flames (i.e. $H_{\mathrm{L}} \sim U_{0} \tau_{\text {ig,st }}^{2}[6]$ ) is also shown in Fig. 16 to compare with the actual $H_{\mathrm{L}}$. Note that the fitting coefficients for $H_{\mathrm{L}}=\alpha U_{0} \tau_{\mathrm{ig}, \mathrm{st}}^{2}+\beta$ are obtained from the data between $L_{\mathrm{res}}=0$ and $8 \mathrm{~m}$. Based on the radial location of the flamebase and $\left(T_{\max }-T_{0}\right) / T_{\mathrm{ig}}[11]$, we categorize the DME jet flames into four different regimes: Regime I or the MILD combustion regime - the lifted flame with MILD combustion with $\left(T_{\max }-T_{0}\right) / T_{\text {ig }}<1$ and the flamebase being located at the centerline; Regime III or the tribrachial edge flame regime - the lifted flame with tribrachial edge with $\left(T_{\max }-T_{0}\right) / T_{\text {ig }}>1$ and the flamebase being located radially outside the centerline; Regime II or the transition regime - the transition regime between Regimes I and III with $\left(T_{\max }-T_{0}\right) / T_{\text {ig }}<1$ and the flamebase being located radially outside the centerline; Regime IV or the attached flame regime - the attached flame to the fuel tube exit with $\left(T_{\max }-T_{0}\right) / T_{\text {ig }}>1$.

In Regime I or the MILD combustion regime $\left(0 \leq L_{\mathrm{res}} \leq 8 \mathrm{~m}\right)$, the lifted flames exhibit MILD combustion structure with being $\left(T_{\max }-T_{0}\right) / T_{\text {ig }}<1$ as shown in Fig. 16b. In this regime, $H_{\mathrm{L}}$ exhibits a U-shaped behavior and is well correlated with $U_{0} \tau_{\mathrm{ig}, \mathrm{st}}^{2}$, indicating that the U-shaped behavior in this regime is primarily attributed to $\tau_{\mathrm{ig}, \mathrm{st}}$ induced by the DME pyrolysis or the 0-D ignition characteristics of the DME/air mixture. The differential diffusion effect induced by DME pyrolysis is not significant for this regime.

In Regime III or the tribrachial edge flame regime $\left(13.5 \leq L_{\mathrm{res}}<17 \mathrm{~m}\right)$, the lifted flames 

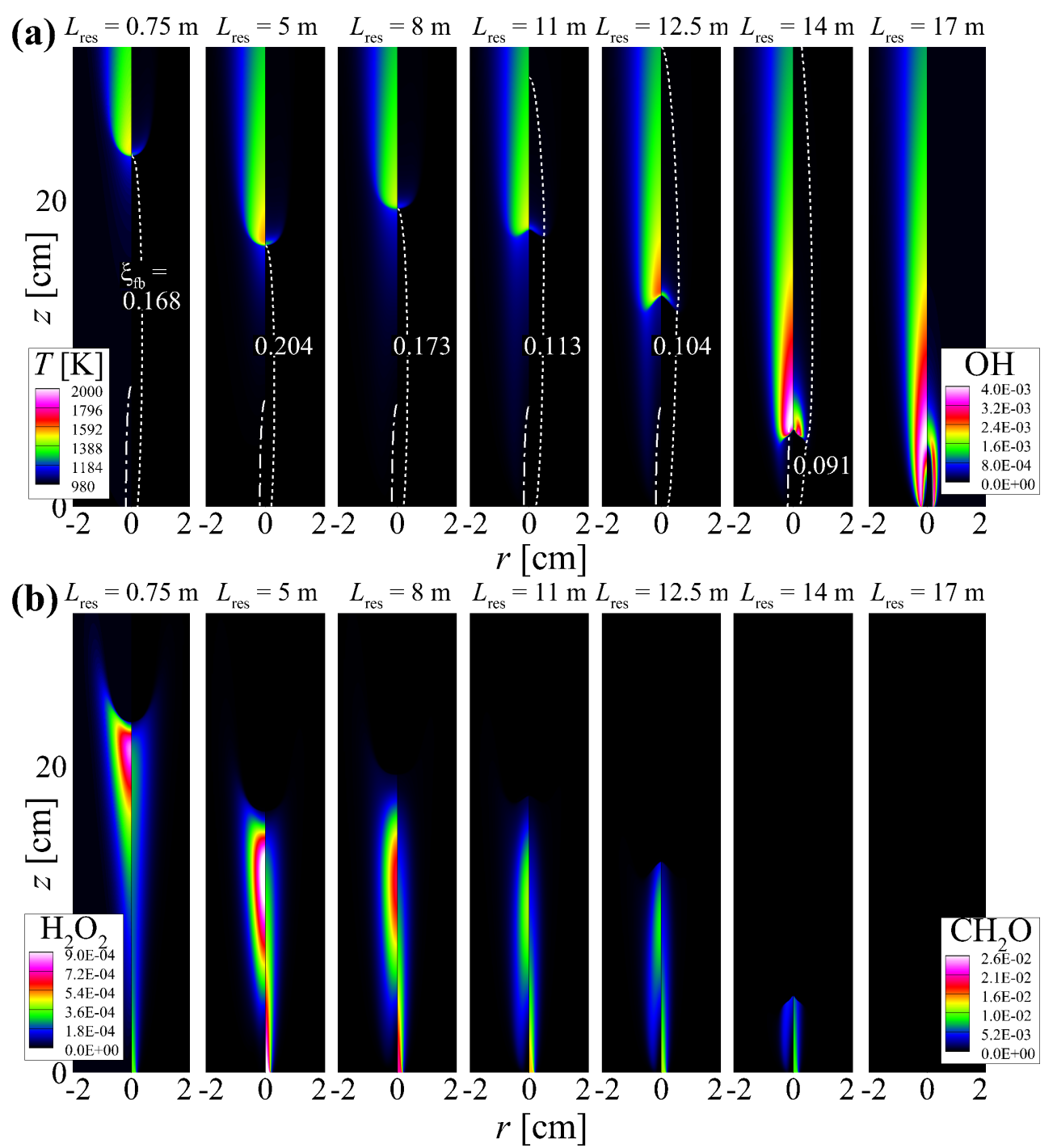

Figure 15: Isocontours of (a) $T$ (left half) and $Y_{\mathrm{OH}}$ (right half) and (b) $Y_{\mathrm{H}_{2} \mathrm{O}_{2}}$ (left half) and $Y_{\mathrm{CH}_{2} \mathrm{O}}$ (right half) for autoignited laminar DME jet flames for various $L_{\text {res }}$ with $T_{0}=980 \mathrm{~K}$ and $X_{\mathrm{F}, 0}=0.08$ at a fixed $U_{\mathrm{F}}=1.53 \mathrm{~m} / \mathrm{s}$. The dashed and dash-dot lines in (a) represent the mixture fraction isoline passing through the flamebase, $\xi_{\mathrm{fb}}$, and the stoichiometric mixture fraction isoline, $\xi_{\mathrm{st}}=0.472$, respectively. 

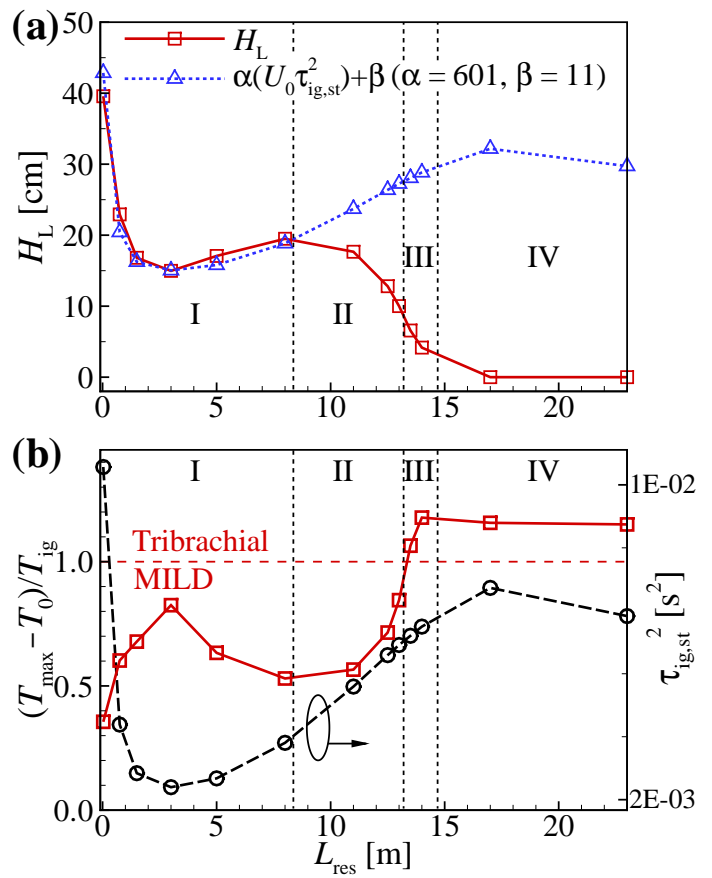

Figure 16: Variations of (a) $H_{\mathrm{L}}$ and its fitting curve (b) $\left(T_{\max }-T_{0}\right) / T_{\mathrm{ig}}$ and $\tau_{\mathrm{ig}, \mathrm{st}}^{2}$ as a function of $L_{\mathrm{res}}$ for the DME jet flames with $T_{0}=980 \mathrm{~K}, X_{\mathrm{F}, 0}=0.08$, and $U_{\mathrm{F}}=1.53 \mathrm{~m} / \mathrm{s}$.

exhibit the tribrachial edge structure with $\left(T_{\max }-T_{0}\right) / T_{\mathrm{ig}}$ being above unity while $H_{\mathrm{L}}$ keeps decreasing with increasing $L_{\text {res }}$. In this regime, more than $90 \%$ of the initial DME is decomposed into small species such as $\mathrm{CH}_{4}, \mathrm{H}_{2}$, and $\mathrm{CO}$ at the fuel tube exit, and hence, the characteristics of the jet flames changes to those of $\mathrm{CH}_{4} / \mathrm{H}_{2} / \mathrm{CO}$ flames rather than those of DME flames. To further understand the characteristics of $H_{\mathrm{L}}$ behavior in this regime, we carried out transient numerical simulations of cases with $L_{\text {res }}=1.5$ and $14 \mathrm{~m}$, which represents MILD combustion and tribrachial edge flame regimes, respectively (see supplementary material). For case with $L_{\text {res }}=1.5 \mathrm{~m}$ in the MILD combustion regime, an ignition kernel develops at the centerline, while for case with $L_{\text {res }}=14 \mathrm{~m}$ in the tribrachial edge flame regime, it does radially outside the centerline. This indicates that the amount of small species that diffuse out from the fuel jet becomes high enough to form the ignition kernel outside the centerline. Therefore, the fast diffusion rates of small species serve to decrease $H_{\mathrm{L}}$ of the tribrachial edge flames for which the flamebase lies outside the centerline. This result shows the different role of the differential diffusion effect on $H_{\mathrm{L}}$ behavior depending 
on the location of the flamebase: in the MILD combustion regime, the differential diffusion effect increases $H_{\mathrm{L}}$ since the flamebase locates at the centerline; in the tribrachial edge flame regime, it decreases $H_{\mathrm{L}}$ since the flamebase locates radially outside the centerline, which is consistent with our previous study [11].

In Regime II or the transition regime $\left(8<L_{\text {res }}<13.5 \mathrm{~m}\right)$, the flamebase locates radially outside the centerline although $\left(T_{\max }-T_{0}\right) / T_{\mathrm{ig}}$ is still below unity. This regime represents the transition of the lifted DME jet flame from the MILD combustion to the tribrachial edge flame. $H_{\mathrm{L}}$ decreases with increasing $L_{\mathrm{res}}$ and starts to deviate from the prediction of $U_{0} \tau_{\mathrm{ig}, \mathrm{st}}^{2}$, which indicates that the degree of DME pyrolysis and the resultant differential diffusion effect become large enough to move the flamebase radially outside, consequently decreasing $H_{\mathrm{L}}$.

In Regime IV or the attached flame regime $\left(L_{\mathrm{res}} \geq 17 \mathrm{~m}\right)$, the DME jet flame is attached to the nozzle with $\left(T_{\max }-T_{0}\right) / T_{\text {ig }}$ being greater than unity. The more DME is decomposed with increasing $L_{\text {res }}$, the more amount of small species is transferred to the flamebase located at the outside the centerline. As a result, the propagation speed of the lifted flames continuously increases with increasing $L_{\text {res }}$, consequently leading to the attachment of the flames.

In summary, the pyrolysis of the DME jet and/or the resultant differential diffusion effect can change the flame structure and the stabilization mechanism of the autoignited lifted DME jet flames, which leads to the non-monotonic $H_{\mathrm{L}}$ behavior with increasing $L_{\text {res }}$. Note that it is of importance to identify a thermodynamic regime where the DME pyrolysis effect becomes significant to the stabilization of autoignited laminar lifted DME jet flames. However, their liftoff characteristics are highly affected not only by the degree of DME pyrolysis at different pressures, temperatures, and fuel dilutions, but also by the degree of differential diffusion induced by the pyrolysis and the fuel jet velocity. Thus, more extensive experimental and numerical studies are required to generalize the effects of DME pyrolysis, which will be left for future research. 


\section{Conclusions}

The characteristics of autoignited laminar lifted DME jet flames in heated coflow air were numerically investigated with a 55-species detailed chemical kinetic mechanism of the DME oxidation. The detailed numerical simulations were performed for various fuel jet velocities and fuel tube lengths using the laminarSMOKE code. The present numerical simulations successfully captured the unusual U-shaped liftoff height behavior of the highlydiluted DME fuel jet flame with increasing fuel jet velocity under autoignitive temperature condition, which is qualitatively similar to that observed in experiments. Additional simulations with the modified mass diffusivity of hydrogen were also performed to understand the unusual U-shaped $H_{\mathrm{L}}$ behavior, which was not fully explained by previous experiment. The species transport, displacement speed, and chemical explosive mode analyses elucidated the detailed stabilization and ignition characteristics of the lifted flames. To further investigate the pyrolysis effect on the autoignited lifted flame, additional numerical simulations were performed by changing the fuel tube length $L_{\text {res }}$ from 0 to $23 \mathrm{~m}$. The numerical results showed the non-monotonic $H_{\mathrm{L}}$ behavior with $L_{\text {res }}$. The following results are obtained from the present study.

1. From the simulations with normal and modified $D_{\mathrm{H}_{2}}$, it is verified that the U-shaped $H_{\mathrm{L}}$ behavior is primary attributed to the fast diffusion rate of $\mathrm{H}_{2}$. Since the DME jet is readily decomposed into small species such as $\mathrm{CH}_{4}, \mathrm{H}_{2}$, and $\mathrm{CO}$ in the heated fuel tube, the different mass diffusivities of the species generated from the pyrolysis of DME cause the unusual U-shaped $H_{\mathrm{L}}$ behavior.

2. The species transport budget and displacement speed analyses revealed that the lifted flames in the increasing $H_{\mathrm{L}}$ regime are stabilized by autoignition-assisted flame propagation mode. Furthermore, the stabilization characteristics of these flames do not depend on $U_{0}$ because the differential diffusion effect is marginal. For the decreasing $H_{\mathrm{L}}$ regime where the differential diffusion effect becomes significant, the flame stabilization mechanism readily changes from the autoignition-assisted flame propagation to the autoignition mode with decreasing $U_{0}$. The flame becomes leaner as the differ- 
ential diffusion effect increases, and consequently the stabilization of lifted flames are more dependent on the autoignition mode.

3. CEMA identified the important variables and reactions contributing to the autoignition of the DME jet. For the increasing $H_{\mathrm{L}}$ regime, the overall autoignition characteristics are not much affected by $U_{0}$. For the decreasing $H_{\mathrm{L}}$ regime, on the other hand, the autoignition characteristics are highly affected by the differential diffusion effect, and thus, the ignition delay and resultant $H_{\mathrm{L}}$ change with $U_{0}$. The results indicate that $0-\mathrm{D}$ homogeneous ignition delay time, $\tau_{\mathrm{ig}, \mathrm{st}}$, does not always represent the autoignition characteristics of 2-D jet flames, especially for the highly diffusive fuels.

4. Based on the characteristics of the DME jet flames with different $L_{\text {res }}$, we categorized them into four different regimes: (I) the MILD combustion regime, (II) the transition regime, (III) the tribrachial edge flame regime, and (IV) the attached flame regime. In the MILD combustion regime, the pyrolysis of the DME jet is negligible for the relatively low $L_{\text {res }}$. The differential diffusion effect of small species generated by the DME pyrolysis starts to affect the lifted flame as $L_{\text {res }}$ increases. From the transition to the tribrachial edge flame and to the attached flame regime, $H_{\mathrm{L}}$ keeps decreasing, which is primarily attributed to the increasing differential diffusion effect induced by the pyrolysis of the DME jet.

\section{Acknowledgments}

This work was supported by Basic Science Research Program through the National Research Foundation of Korea (NRF) funded by the Ministry of Science and ICT (NRF2018R1A2A2A05018901). SHC was supported by KAUST. This research used the resources of the KAUST Supercomputing Laboratory and UNIST Supercomputing Center. We would like to thank Prof. T. Lu at the University of Connecticut for valuable discussions.

\section{References}

[1] L. M. Pickett, Low flame temperature limits for mixing-controlled Diesel combustion, Proc. Combust. Inst. 30 (2005) 2727-2735. 
[2] J. E. Dec, Advanced compression-ignition engines-understanding the in-cylinder processes, Proc. Combust. Inst. 32 (2009) 2727-2742.

[3] C. S. Yoo, R. Sankaran, J. H. Chen, Three-dimensional direct numerical simulation of a turbulent lifted hydrogen jet flame in heated coflow: flame stabilization and structure, J. Fluid Mech. 640 (2009) 453-481.

[4] C. S. Yoo, E. S. Richardson, R. Sankaran, J. H. Chen, A DNS study on the stabilization mechanism of a turbulent lifted ethylene jet flame in highly-heated coflow, Proc. Combust. Inst. 33 (2011) 1619-1627.

[5] O. Schulz, T. Jaravel, T. Poinsot, B. Cuenot, N. Noiray, A criterion to distinguish autoignition and propagation applied to a lifted methane-air jet flame, Proc. Combust. Inst. 36 (2016) 1-8.

[6] B. C. Choi, K. N. Kim, S. H. Chung, Autoignited laminar lifted flames of propane in coflow jets with tribrachial edge and mild combustion, Combust. Flame 156 (2009) 396-404.

[7] B. C. Choi, S. H. Chung, Autoignited laminar lifted flames of methane, ethylene, ethane, and n-butane jets in coflow air with elevated temperature, Combust. Flame 157 (2010) 2348-2356.

[8] B. C. Choi, S. H. Chung, Autoignited laminar lifted flames of methane/hydrogen mixtures in heated coflow air, Combust. Flame 159 (2012) 1481-1488.

[9] S. M. Al-Noman, S. K. Choi, S. H. Chung, Numerical study of laminar nonpremixed methane flames in coflow jets: Autoignited lifted flames with tribrachial edges and MILD combustion at elevated temperatures, Combust. Flame 171 (2016) 119-132.

[10] S. M. Al-Noman, B. C. Choi, S. H. Chung, Autoignited lifted flames of dimethyl ether in heated coflow air, Combust. Flame 195 (2018) 75-83.

[11] K. S. Jung, S. O. Kim, T. Lu, S. H. Chung, B. J. Lee, C. S. Yoo, Differential diffusion effect on the stabilization characteristics of autoignited laminar lifted methane/hydrogen jet flames in heated coflow air, Combust. Flame 198 (2018) 305-319.

[12] A. Krisman, E. R. Hawkes, M. Talei, A. Bhagatwala, J. H. Chen, Polybrachial structures in dimethyl ether edge-flames at negative temperature coefficient conditions, Proc. Combust. Inst. 35 (2015) 9991006.

[13] A. Krisman, E. R. Hawkes, J. H. Chen, The structure and propagation of laminar flames under autoignitive conditions, Combst. Flame. 188 (2018) 399-411.

[14] S. Deng, P. Zhao, M. E. Mueller, C. K. Law, Autoignition-affected stabilization of laminar nonpremixed DME/air coflow flames, Combust. Flame 162 (2015) 3437-3445.

[15] S. Deng, P. Zhao, M. E. Mueller, C. K. Law, Stabilization of laminar nonpremixed DME/air coflow flames at elevated temperatures and pressures, Combust. Flame 162 (2015) 4471-4478.

[16] J. Buckmaster, Edge-flames, Prog. Energy Combust. Sci 28 (2002) 435-475.

[17] S. H. Chung, Stabilization, propagation and instability of tribrachial triple flames, Proc. Combust. Inst. 
31 (2007) 877-892.

[18] Z. Zhao, M. Chaos, A. Kazakov, F. L. Dryer, Thermal decomposition reaction and a comprehensive kinetic model of dimethyl ether, Int. J. Chem. Kinet 40 (2008) 1-18.

[19] S. H. Park, C. S. Lee, Applicability of dimethyl ether (DME) in a compression ignition engine as an alternative fuel, Energy Convers. Manage. 86 (2014) 848-863.

[20] C. Arcoumanis, C. Bae, R. Crokkers, E. Kinoshita, The potential of di-methyl ether (DME) as an alternative fuel for compression-ignition engines: a review, Fuel 87 (2008) 1014-1030.

[21] S. K. Choi, S. Al-Noman, S. H. Chung, Simulation of non-autoignited and autoignited laminar nonpremixed jet flames of syngas in heated coflow air, Combust. Sci. Technol. 187 (2015) 132-147.

[22] J. J. Nash, J. S. Francisco, Unimolecular decomposition pathways of dimethyl ether: An ab initio study, J. Phys. Chem. A 102 (1998) 236-241.

[23] S. L. Fischer, F. L. Dryer, H. J. Curran, The reaction kinetics of dimethyl ether. I: High-temperature pyrolysis and oxidation in flow reactors, Int. J. Chem. Kinet 32 (2000) 713-740.

[24] A. Cuoci, A. Frassoldati, T. Faravelli, E. Ranzi, A computational tool for the detailed kinetic modeling of laminar flames: Application to $\mathrm{C}_{2} \mathrm{H}_{4} / \mathrm{CH}_{4}$ coflow flames, Combust. Flame 160 (2013) 870-886.

[25] A. Cuoci, A. Frassoldati, T. Faravelli, E. Ranzi, Numerical modeling of laminar flames with detailed kinetics based on the operator-splitting method, Energy Fuels 27 (2013) 7730-7753.

[26] H. G. Weller, G. Tabor, H. Jasak, C. Fureby, A tensorial approach to computational continuum mechanics using object-oriented techniques, Comput. Phys. 12 (1998) 620-631.

[27] K. Kuwahara, H. Ando, M. Furutani, Y. Ohta, Impact of formaldehyde addition on auto-ignition in internal-combustion engines, JSME Int. J. Ser. B 48 (2005) 708-716.

[28] H. Yamada, K. Suzaki, A. Tezaki, Y. Goto, Transition from cool flame to thermal flame in compression ignition process, Combust. Flame 154 (2008) 248-258.

[29] A. Cavaliere, M. de Joannon, Mild combustion, Prog. Energy Combust. Sci. 30 (2004) 329-366.

[30] Y. Minamoto, N. Swaminathan, R. S. Cant, T. Leung, Reaction zones and their structure in MILD combustion, Combust. Sci. Technol. 186 (2014) 1075-1096.

[31] Y. Hidaka, K. Sato, M. Yamane, High-temperature pyrolysis of dimethyl ether in shock waves, Combst. Flame 123 (2000) 1-22.

[32] H. Hashemi, J. M. Christensen, P. Glarborg, High-pressure pyrolysis and oxidation of DME and DME/ $\mathrm{CH}_{4}$, Combst. Flame 205 (2019) 80-92.

[33] C. B. Reuter, R. Zhang, O. R. Yehia, Y. Rezgui, Y. Ju, Counterflow flame experiments and chemical kinetic modeling of dimethyl ether/methane mixtures, Combust. Flame 196 (2018) 1-10.

[34] T. Lu, C. S. Yoo, J. H. Chen, C. K. Law, Three-dimensional direct numerical simulation of a turbulent lifted hydrogen jet flame in heated coflow: a chemical explosive mode analysis, J. Fluid Mech. 652 
(2010) 45-64.

[35] Z. Luo, C. S. Yoo, E. S. Richardson, J. H. Chen, C. K. Law, T. Lu, Chemical explosive mode analysis for a turbulent lifted ethylene jet flame in highly-heated coflow, Combust. Flame 159 (2012) 265-274.

[36] R. Shan, C. S. Yoo, J. H. Chen, T. Lu, Computational diagnostics for $n$-heptane flames with chemical explosive mode analysis, Combust. Flame 159 (2012) 3119-3127.

[37] M. B. Luong, G. H. Yu, S. H. Chung, C. S. Yoo, Ignition of a lean PRF/air mixture under RCCI/SCCI conditions: Chemical aspects, Proc. Combust. Inst. 36 (2017) 3587-3596.

[38] L. Cifuentes, E. Fooladgar, C. Duwig, Chemical explosive mode analysis for a jet-in-hot-coflow burner operating in MILD combustion, Fuel 232 (2018) 712-723.

[39] R. W. Bilger, The structure of turbulent nonpremixed flames, Symp. (Int.) Combust. 22 (1988) 475-488.

[40] S. K. Choi, S. H. Chung, Autoignited and non-autoignited lifted flames of pre-vaporized $n$-heptane in coflow jets at elevated temperatures, Combust. Flame 160 (2013) 1717-1724.

[41] S. M. Al-Noman, S. K. Choi, S. H. Chung, Autoignition characteristics of laminar lifted jet flames of pre-vaporized iso-octane in heated coflow air, Fuel 162 (2015) 171-178.

[42] J. H. Chen, E. R. Hawkes, R. Sankaran, S. D. Mason, H. G. Im, Direct numerical simulation of ignition front propagation in a constant volume with temperature inhomogeneities I. Fundamental analysis and diagnostics, Combust. Flame. 145 (2006) 128-144.

[43] R. L. Gordon, A. R. Masri, S. B. Pope, G. M. Goldin, Transport budgets in turbulent lifted flames of methane autoigniting in a vitiated co-flow, Combust. Flame. 151 (2007) 495-511.

[44] O. Schulz, N. Noiray, Autoignition flame dynamics in sequential combustors, Combst. Flame. 192 (2018) $86-100$.

[45] X. Gao, S. Yang, B. Wu, W. Sun, The effects of ozonolysis activated autoignition on non-premixed jet flame dynamics: a numerical and experimental study, 53 ${ }^{\text {rd }}$ AIAA/SAE/ASEE Joint Propulsion Conference (2017) 2017-4774.

[46] Y. B. Zel'dovich, Regime classification of an exothermic reaction with nonuniform initial conditions, Combust. Flame. 39 (1980) 211-226.

[47] C. H. Gibson, Find structure of scalar fields mixed by turbulence. I. Zero-gradient points and minimal gradient surfaces, Phys. Fluids 11 (1968) 2305-2315.

[48] T. Echekki, J. H. Chen, Structure and propagation of methanol-air triple flames, Combust. Flame 114 (1998) 231-245.

[49] H. G. Im, J. H. Chen, Structure and propagation of triple flames in partially premixed hydrogen-air mixtures, Combust. Flame 119 (1999) 436-454.

[50] H. S. Bak, S. R. Lee, J. H. Chen, C. S. Yoo, A numerical study of the diffusive-thermal instability of opposed nonpremixed tubular flames, Combust. Flame 162 (2015) 4612-4621. 
[51] S. O. Kim, M. B. Luong, J. H. Chen, C. S. Yoo, A DNS study of the ignition of lean PRF/air mixtures with temperature inhomogeneities under high pressure and intermediate temperature, Combust. Flame 162 (2015) 717-726.

[52] H. S. Bak, C. S. Yoo, Flame instabilities and flame cell dynamics in opposed nonpremixed tubular flames with radiative heat loss, Combust. Flame 194 (2018) 322-333.

[53] C. S. Yoo, T. Lu, J. H. Chen, C. K. Law, Direct numerical simulations of ignition of a lean $n$-heptane/air mixture with temperature inhomogeneities at constant volume: Parametric study, Combust. Flame 158 (2011) 1727-1741.

[54] R. Sankaran, Propagation velocity of a deflagration front in a preheated autoigniting mixture, $9^{\text {th }}$ US National Combustion Meeting.

[55] R. W. Grout, A. Gruber, C. S. Yoo, J. H. Chen, Direct numerical simulation of flame stabilization downstream of a transverse fuel jet in cross flow, Proc. Combust. Inst. 33 (2011) 1629-1637.

[56] H. Kolla, R. W. Grout, A. Gruber, J. H. Chen, Mechanisms of flame stabilization and blowout in a reacting turbulent hydrogen jet in cross-flow, Combust. Flame 159 (2012) 2755-2766.

[57] M. B. Luong, Z. Luo, T. Lu, S. H. Chung, C. S. Yoo, Direct numerical simulations of the ignition of lean primary reference fuel/air mixtures with temperature inhomogeneities, Combust. Flame 160 (2013) 2038-2047.

[58] M. B. Luong, T. Lu, S. H. Chung, C. S. Yoo, Direct numerical simulations of the ignition of a lean biodiesel/air mixture with temperature and composition inhomogeneities at high pressure and intermediate temperature, Combust. Flame 161 (2014) 2878-2889.

[59] M. B. Luong, G. H. Yu, T. Lu, S. H. Chung, C. S. Yoo, Direct numerical simulations of ignition of a lean $n$-heptane/air mixture with temperature and composition inhomogeneities relevant to HCCI and SCCI combustion, Combust. Flame 162 (2015) 4566-4585.

[60] C. Xu, J.-W. Park, C. S. Yoo, J. H. Chen, T. Lu, Identification of premixed flame propagation modes using chemical explosive mode analysis, Proc. Combust. Inst. 37 (2019) 2407-2415.

[61] G. H. Yu, M. B. Luong, S. H. Chung, C. S. Yoo, Ignition characteristics of a temporally evolving $n$ heptane jet in an iso-octane/air stream under RCCI combustion-relevant conditions, Combust. Flame 208 (2019) 299-312.

[62] C. K. Westbrook, Chemical kinetics of hydrocarbon ignition in practical combustion systems, Proc. Combust. Inst. 28 (2000) 1563-1577.

[63] P. Dagaut, J. Boettner, M. Cathonnet, Chemical kinetic study of dimethyl ether oxidation in a jet stirred reaction from 1 to 10 atm: experiments and kinetic modeling, Symp. (Int.) Combust. 26 (1996) $627-632$.

[64] P. Dagaut, C. Daly, J. M. Simmie, M. Cathonnet, The oxidation and ignition of dimethylether from 
low to high temperature $(500-1600 \mathrm{~K})$ : experiments and kinetic modeling, Symp. (Int.) Combust. 27 (1998) 361-369.

[65] G. Bansal, A. Mascarenhas, J. H. Chen, Direct numerical simulations of autoignition in stratified dimethyl-ether(DME)/air turbulent mixtures, Combust. Flame 162 (2015) 688-702.

[66] C. K. Law, Combustion Physics, Cambridge University Press, 2006. 